\title{
New chemical scheme for studying carbon-rich exoplanet atmospheres
}

\author{
Olivia Venot ${ }^{1}$, Eric Hébrard ${ }^{2}$, Marcelino Agúndez ${ }^{3,4,5}$, Leen Decin $^{1}$, and Roda Bounaceur ${ }^{2}$ \\ 1 Instituut voor Sterrenkunde, Katholieke Universiteit Leuven, Celestijnenlaan 200D, 3001 Leuven, Belgium \\ e-mail: olivia.venot@ster . kuleuven.be \\ 2 Laboratoire Réactions et Génie des Procédés, LRGP UMP 7274 CNRS, Université de Lorraine, 1 rue Grandville, BP 20401, \\ 54001 Nancy, France \\ 3 Instituto de Ciencia de Materiales de Madrid, CSIC, C/Sor Juana Inés de la Cruz 3, 28049 Cantoblanco, Spain \\ ${ }^{4}$ Univ. Bordeaux, LAB, UMR 5804, 33270, Floirac, France \\ 5 CNRS, LAB, UMR 5804, 33270, Floirac, France
}

Received 10 November 2014 / Accepted 11 February 2015

\begin{abstract}
Context. While the existence of more than 1800 exoplanets have been confirmed, there is evidence of a wide variety of elemental chemical composition, that is to say different metallicities and $\mathrm{C} / \mathrm{N} / \mathrm{O} / \mathrm{H}$ ratios. Atmospheres with a high $\mathrm{C} / \mathrm{O}$ ratio (above 1) are expected to contain a high quantity of hydrocarbons, including heavy molecules (with more than two carbon atoms). To correctly study these C-rich atmospheres, a chemical scheme adapted to this composition is necessary.

Aims. We have implemented a chemical scheme that can describe the kinetics of species with up to six carbon atoms $\left(\mathrm{C}_{0}-\mathrm{C}_{6} \mathrm{scheme}\right)$. This chemical scheme has been developed with combustion specialists and validated by experiments that were conducted on a wide range of temperatures $(300-2500 \mathrm{~K})$ and pressures $(0.01-100 \mathrm{bar})$.

Methods. To determine for which type of studies this enhanced chemical scheme is mandatory, we created a grid of 12 models to explore different thermal profiles and $\mathrm{C} / \mathrm{O}$ ratios. For each of them, we compared the chemical composition determined with a $\mathrm{C}_{0}-\mathrm{C}_{2}$ chemical scheme (species with up to two carbon atoms) and with the $\mathrm{C}_{0}-\mathrm{C}_{6}$ scheme. We also computed synthetic spectra corresponding to these 12 models.

Results. We found no difference in the results obtained with the two schemes when photolyses were excluded from the model, regardless of the temperature of the atmosphere. In contrast, differences can appear in the upper atmosphere $(P>\sim 1-10$ mbar $)$ when there is photochemistry. These differences are found for all the tested pressure-temperature profiles if the $\mathrm{C} / \mathrm{O}$ ratio is above 1 . When the $\mathrm{C} / \mathrm{O}$ ratio of the atmosphere is solar, differences are only found at temperatures lower than $1000 \mathrm{~K}$. The differences linked to the use of different chemical schemes have no strong influence on the synthetic spectra. However, with this study, we have confirmed $\mathrm{C}_{2} \mathrm{H}_{2}$ and $\mathrm{HCN}$ as possible tracers of warm C-rich atmospheres.

Conclusions. The use of this new chemical scheme (instead of the $\mathrm{C}_{0}-\mathrm{C}_{2}$ ) is mandatory for modelling atmospheres with a high $\mathrm{C} / \mathrm{O}$ ratio and, in particular, for studying the photochemistry in detail. If the focus is on the synthetic spectra, a smaller scheme may be sufficient, because it will be faster in terms of computation time.
\end{abstract}

Key words. astrochemistry - planets and satellites: atmospheres - planets and satellites: composition

\section{Introduction}

Observing spectra of transiting exoplanets has proven to be an excellent way of obtaining information on the chemical composition of their atmospheres. To date, only a few chemical species $\left(\mathrm{H}, \mathrm{H}_{2} \mathrm{O}, \mathrm{CO}_{2}, \mathrm{CH}_{4}, \mathrm{CO}, \mathrm{HCN}, \mathrm{K}, \mathrm{Na}\right)$ have been inferred thanks to this technique (e.g. Charbonneau et al. 2002; Désert et al. 2008; Redfield et al. 2008; Swain et al. 2009a,b; Sing et al. 2011; Madhusudhan et al. 2014a). Accordingly, one of the main goals of chemical models of exoplanet atmospheres is to find the elemental composition and the chemical processes that lead to the observed abundances, adjusting different parameters such as the metallicity, the $\mathrm{C} / \mathrm{O}$ elemental abundance ratio, or the strength of vertical mixing (i.e. Kopparapu et al. 2012; Miller-Ricci Kempton et al. 2012; Moses et al. 2013a,b; Venot et al. 2014; Agúndez et al. 2014b).

The existence of carbon-rich exoplanets has been suggested for the first time by Madhusudhan et al. (2011a) who analysed the Spitzer spectra of WASP-12b. Nevertheless, a C/O ratio $\geq 1$ in the atmosphere of this planet is quite controversial. Several studies have found that the atmosphere of WASP-12b could either have a solar $\mathrm{C} / \mathrm{O}$ ratio $(0,54)$ or be $\mathrm{C}$-rich (Crossfield et al. 2012; Swain et al. 2013; Mandell et al. 2013; Stevenson et al. 2014; Madhusudhan et al. 2014a). To clearly conclude on the composition of this planet, more observations with high precision are necessary, using for instance the Wide Field Camera 3 instrument on the Hubble Space Telescope (McCullough \& MacKenty 2012). However, Madhusudhan (2012) and Moses et al. (2013a) studied the influence of the C/O ratio on the chemical composition of hot Jupiter atmospheres. They found that models with a $\mathrm{C} / \mathrm{O}$ ratio $\sim 1$ agreed with observational spectra of WASP-12b, XO-1b, and CoRoT-2b, which indicates that a wide variety of $\mathrm{C} / \mathrm{O}$ ratios might be indeed possible in exoplanet atmospheres.

To study the chemical composition of carbon-rich atmospheres, photochemical models must use chemical schemes adapted to this carbon enrichment. When the $\mathrm{C} / \mathrm{O}$ ratio increases, more complex carbon species are produced. Thus, carbon-rich atmospheres are expected to contain heavy hydrocarbons with 
significant abundances that need to be included in the chemical scheme used in the modelling. Most of chemical schemes (primarily constructed to study atmospheres with solar abundances) do not contain such complex species and can consequently give biased results. Kopparapu et al. (2012) studied the atmosphere of WASP-12b with two different C/O ratios (solar and twice solar), but their chemical scheme only contained 31 molecules, the heaviest hydrocarbon being $\mathrm{C}_{2} \mathrm{H}_{2}$. Thus, the abundance of some hydrocarbons may be over- or underestimated because heavier molecules are absent from the chemical scheme. On the other hand, Moses et al. (2013a) used a more complex chemical scheme (90 species), which extends up to $\mathrm{C}_{6} \mathrm{H}_{6}$, which allows describing the more important hydrocarbons.

Nevertheless, the question of the robustness and the completeness of chemical schemes is not addressed in many publications that examine photochemical models. The chemical schemes are constructed from reaction networks that were originally made for Jovian planets (Liang et al. 2003, 2004; Line et al. 2010, 2011; Moses et al. 2011, 2013a) in which, in the best cases (e.g. not for Liang et al. 2003, 2004), hightemperature reactions have been added and forward reactions have been reversed to reproduce the thermochemical equilibrium in absence of out-of-equilibrium processes (Visscher \& Moses 2011; Venot et al. 2012). Zahnle et al. (2009) modestly describe the method they used to construct their chemical scheme: reaction rates were taken from the NIST database ${ }^{1}$, and they chose by order of decreasing priority between reported reaction rates according to relevant temperature range, newest review, newest experiment, and newest theory. Venot et al. (2012) presented the first chemical scheme that was validated as a whole by experiment. Their chemical scheme was constructed in collaboration with combustion specialists and was experimentally validated on a wide range of temperatures $(300-2500 \mathrm{~K})$ and pressures $(0.001-100 \mathrm{bar})$, making this one of the currently most reliable chemical schemes. It is able to describe the kinetics of species containing up to two carbon atoms.

The $\mathrm{C}_{0}-\mathrm{C}_{2}$ scheme may be insufficient, for studying atmospheres enriched in heavier hydrocarbons (with more than two carbon atoms). That is why we have developed an extended version of the chemical scheme of Venot et al. (2012), with species containing up to six carbon atoms. In Sect. 2 we present this new chemical scheme and the grid of models we constructed to test it. In Sect. 3 we present the results obtained with the $\mathrm{C}_{0}-\mathrm{C}_{6}$ scheme and compare them with those obtained with the $\mathrm{C}_{0}-\mathrm{C}_{2}$ scheme. In Sect. 4, we discuss the implications for interpreting transmission and emission spectra of exoplanet atmospheres and identify species that could play the role of tracers for warm $\mathrm{C}$-rich atmospheres.

\section{Model}

\subsection{Chemical scheme}

\subsubsection{Reaction network}

The $\mathrm{C}_{0}-\mathrm{C}_{6}$ reaction scheme includes the $\mathrm{C}_{0}-\mathrm{C}_{2}$ reaction network described in Venot et al. (2012), but also reactions of $\mathrm{C}_{3}-\mathrm{C}_{6}$ unsaturated species, such as $\mathrm{C}_{3} \mathrm{H}_{6}$ (propene) or $\mathrm{C}_{4} \mathrm{H}_{6}$ (butadiene), as well as reactions of small aromatic compounds up to

\footnotetext{
1 http://kinetics.nist.gov/kinetics
}

$\mathrm{C}_{8} \mathrm{H}_{10}$ (ethylbenzene). The base of reactions includes the following sub-mechanisms:

- A primary mechanism including reactions of $\mathrm{C}_{7} \mathrm{H}_{8}$ (toluene) and of $\mathrm{C}_{7} \mathrm{H}_{7}$ (benzyl), $\mathrm{C}_{6} \mathrm{H}_{4} \mathrm{CH}_{3}$ (methylphenyl), $\mathrm{C}_{6} \mathrm{H}_{5} \mathrm{CH}_{2} \mathrm{OO}$ (peroxybenzyl), $\mathrm{C}_{6} \mathrm{H}_{5} \mathrm{CH}_{2} \mathrm{O}$ (alcoxy benzyl), $\mathrm{HOC}_{6} \mathrm{H}_{4} \mathrm{CH}_{2} \mathrm{O}$ (hydroxyalcoxybenzyl), $\mathrm{OC}_{6} \mathrm{H}_{4} \mathrm{CH}_{3}$ (cresoxy), $\mathrm{C}_{6} \mathrm{H}_{5} \mathrm{CHOH}$, and $\mathrm{HOC}_{6} \mathrm{H}_{4} \mathrm{CH}_{2}$ (hydroxybenzyls) free radicals. This mechanism is described in Bounaceur et al. (2005).

- A secondary mechanism involving the reactions of $\mathrm{C}_{6} \mathrm{H}_{5} \mathrm{CHO}$ (benzaldehyde), $\mathrm{C}_{6} \mathrm{H}_{5} \mathrm{CH}_{2} \mathrm{OOH}$ (benzyl hydroperoxide), $\mathrm{HOC}_{6} \mathrm{H}_{4} \mathrm{CH}_{3}$ (cresol), $\mathrm{C}_{6} \mathrm{H}_{5} \mathrm{CH}_{2} \mathrm{OH}$ (benzylalcohol), $\mathrm{C}_{8} \mathrm{H}_{10}$ (ethylbenzene), $\mathrm{C}_{8} \mathrm{H}_{8}$ (styrene), and $\mathrm{C}_{14} \mathrm{H}_{14}$ (bibenzyl). This mechanism is also presented in Bounaceur et al. (2005).

- A mechanism for the oxidation of $\mathrm{C}_{6} \mathrm{H}_{6}$ (benzene) (Da Costa et al. 2003). It includes the reactions of $\mathrm{C}_{6} \mathrm{H}_{6}$ and of $\mathrm{cC}_{6} \mathrm{H}_{7}$ (cyclohexadienyl), $\mathrm{cC}_{6} \mathrm{H}_{5}$ (phenyl), $\mathrm{C}_{6} \mathrm{H}_{5} \mathrm{O}_{2}$ (phenylperoxy), $\mathrm{cC}_{6} \mathrm{H}_{5} \mathrm{O}$ (phenoxy), $\mathrm{OC}_{6} \mathrm{H}_{4} \mathrm{OH}$ (hydroxyphenoxy), $\mathrm{cC}_{5} \mathrm{H}_{5}$ (cyclopentadienyl), $\mathrm{cC}_{5} \mathrm{H}_{5} \mathrm{O}$ (cyclopentadienoxy), and $\mathrm{cC}_{5} \mathrm{H}_{4} \mathrm{OH}$ (hydroxycyclopentadienyl) free radicals, as well as the reactions of $\mathrm{C}_{6} \mathrm{H}_{4} \mathrm{O}_{2}$ (ortho-benzoquinone), $\mathrm{cC}_{6} \mathrm{H}_{5} \mathrm{OH}$ (phenol), $\mathrm{cC}_{5} \mathrm{H}_{6}$ (cyclopentadiene), $\mathrm{cC}_{5} \mathrm{H}_{4} \mathrm{O}$ (cyclopentadienone), $\mathrm{cC}_{5} \mathrm{H}_{5} \mathrm{OH}$ (cyclopentadienol), and $\mathrm{C}_{4} \mathrm{H}_{4} \mathrm{O}$ (vinylketene).

- A mechanism for the oxidation of unsaturated $\mathrm{C}_{3}-\mathrm{C}_{4}$ species. It contains reactions involving $\mathrm{C}_{3} \mathrm{H}_{2}$ (propadienylidene), $\mathrm{C}_{3} \mathrm{H}_{3}$ (prop-3-ynyle), the two isomers a- $\mathrm{C}_{3} \mathrm{H}_{4}$ (allene) and $\mathrm{p}-\mathrm{C}_{3} \mathrm{H}_{4}$ (propyne), the three isomers $\mathrm{C}_{3} \mathrm{H}_{5}$ (allyle), 1- $\mathrm{C}_{3} \mathrm{H}_{5}$ (prop-1-en-2-yle), and 2- $\mathrm{C}_{3} \mathrm{H}_{5}$ (prop-1en-1-yle), $\mathrm{C}_{3} \mathrm{H}_{6}$ (propene), $\mathrm{cC}_{3} \mathrm{H}_{6}$ (cyclopropene), $\mathrm{C}_{4} \mathrm{H}_{2}$ (diacetylene), the two isomers $n-\mathrm{C}_{4} \mathrm{H}_{3}$ (but-1-en-3-ynyle) and $\mathrm{i}-\mathrm{C}_{4} \mathrm{H}_{3}$ (but-1-en-3-yn-2-yle), $\mathrm{C}_{4} \mathrm{H}_{4}$ (vinylacetylene), the five isomers $\mathrm{n}-\mathrm{C}_{4} \mathrm{H}_{5}$ (1,3-butadienyle), $\mathrm{i}-\mathrm{C}_{4} \mathrm{H}_{5}$ (1,3butadien-2-yle), 13- $\mathrm{C}_{4} \mathrm{H}_{5}$ ( but-1-yn-3-yle), 14- $\mathrm{C}_{4} \mathrm{H}_{5}$ (but1-yn-4-yle), and $21-\mathrm{C}_{4} \mathrm{H}_{5}$ (but-2-yn-1-yl), the five isomers 13- $\mathrm{C}_{4} \mathrm{H}_{6}$ (1,3-butadiene), 12- $\mathrm{C}_{4} \mathrm{H}_{6}$ (1,2-butadiene), $\mathrm{cC}_{4} \mathrm{H}_{6}$ (methyl-cyclopropene), 1- $\mathrm{C}_{4} \mathrm{H}_{6}$ (1-butyne), and 2- $\mathrm{C}_{4} \mathrm{H}_{6}$ (2butyne). This sub-mechanism integrates reactions involved in the formation of aromatic compounds and has been developed and validated against experimental data from the literature (Westmoreland et al. 1989; Tsang 1991; Miller \& Melius 1992; Lindstedt \& Maurice 1996; Hidaka et al. 1996; Wang \& Frenklach 1997).

This database has been used with success in modelling of premixed flame of butadiene, propyne, allene, and acetylene (Fournet et al. 1999) and in predicting formation of small aromatic compounds for flame of methane (Gueniche et al. 2009; Belmekki et al. 2002).

To obtain a good chemical overlap between the reactions bases $\mathrm{C}_{0}-\mathrm{C}_{2}$ and $\mathrm{C}_{3}-\mathrm{C}_{6}$, we added a detailed kinetic mechanism for the oxidation of a propane/n-butane mixture. This sub-mechanism includes a comprehensive primary mechanism, where the only molecular reactants considered are the initial organic compounds (here propane and n-butane) and oxygen, and a lumped secondary mechanism that contains the reactions consuming the molecular products of the primary mechanism that do not react in the reaction bases $\mathrm{C}_{0}-\mathrm{C}_{2}$ or $\mathrm{C}_{3}-\mathrm{C}_{6}$. This submechanism has been used with success in modelling laminar flame velocity for components of natural gas (Dirrenberger et al. 2011).

In this reaction base, we included pressure-dependent rate constants for unimolecular decomposition, recombination, 
beta-scission, and additional reactions following the formalism proposed by Troe (1974), as well as third-body efficiency coefficients. As for the $\mathrm{C}_{0}-\mathrm{C}_{2}$ chemical scheme, all the reactions of the $\mathrm{C}_{0}-\mathrm{C}_{6}$ scheme are reversed, which allows reproducing thermochemical equilibrium. Most of them (called "reversible reactions") are reversed through the principle of microscopic reversibility (e.g. $K_{\text {eq }}=k_{\mathrm{f}} / k_{\mathrm{r}}$, with $K_{\mathrm{eq}}$ the equilibrium constant, $k_{\mathrm{f}}$ the reaction rate of the forward reaction, and $k_{\mathrm{r}}$ the reaction rate of the reverse reaction, see Venot et al. 2012 for more details), but a few of them (called "irreversible reactions") are reversed using experimentally measured reaction rates for both the forward and the reverse reaction. This ensures a better reproduction of the out-of-equilibrium experiments.

Thermochemical data for molecules or radicals were calculated and stored as 14 polynomial coefficients according to the CHEMKIN formalism (Kee et al. 1996). These data were calculated using the software THERGAS (Muller et al. 1995), which is based on the group and bond additivity methods proposed by Benson (1976).

In summary, the $\mathrm{C}_{0}-\mathrm{C}_{6}$ reaction base is composed of 240 reactants that are involved in 4002 chemical reactions: 1991 reversible reactions and 20 irreversible reactions. This chemical scheme is available at the online database KIDA ${ }^{2}$ (Wakelam et al. 2012).

\subsubsection{Photolysis}

To model the out-of-equilibrium process that is due to photolysis, we added a set of 113 photodissociations to the $\mathrm{C}_{0}-\mathrm{C}_{6}$ chemical scheme. We modelled the stellar irradiation by using the solar spectrum (Thuillier et al. 2004) in the range [0-900] nm.

For most molecules, no data at high temperature exist, so we used absorption cross-sections at ambient temperature that we found in the MPI-Mainz UV/VIS Spectral Atlas (Keller-Rudek et al. 2013) and in the UV/Vis+ Spectra Data Base ${ }^{3}$. More specific references and explanations of the methodology of calculating cross-sections and quantum yields can be found in Venot et al. (2012), Hébrard et al. (2013), and Dobrijevic et al. (2014). For $\mathrm{CO}_{2}$ (Venot et al. 2013) and $\mathrm{NH}_{3}$ (Venot et al. in prep.), we used our recent measurements at $500 \mathrm{~K}$. As we present in Sect. 2.3, we used three different thermal profiles. For all of them, we used the same cross-sections at $500 \mathrm{~K}$ and did not try to adjust the cross-section of $\mathrm{CO}_{2}$ to the exact temperature at which photodissociations occurred because we are mainly interested in the effect of the new chemical scheme at different atmospheric temperatures. However, we verified with the two different models $\left(T_{1000} \zeta_{0.54}\right.$ and $T_{1000} \zeta_{1.1}$, see Sect. 2.3 and Table 1 for more explanations and the meaning of these symbols) that this approximation has no significant effect on the computed chemical abundances. The differences are always lower than $10 \%$, and for $\mathrm{CO}_{2}$, even lower than $0.54 \%$ for solar $\mathrm{C} / \mathrm{O}$. When $\mathrm{C} / \mathrm{O}=$ 1.1 , the differences are lower than $30 \%$ and lower than $6.7 \%$ for $\mathrm{CO}_{2}$. These differences would not be visible on the abundances profiles figures plotted with a logarithmic scale.

\subsection{OD models}

First we compared the kinetic evolution of species calculated with the two chemical schemes. We used the OD model presented in Venot et al. (2012) that allows determining the chemical evolution of a mixture at a certain pressure and temperature,

\footnotetext{
2 KInetic Database for Astrochemistry:

http://kida.obs.u-bordeaux1.fr/models/

3 http://www.uv-spectra.de/
}

with no photolysis process. We computed several conditions corresponding to the combination of $T=500,800,1000$, or $1500 \mathrm{~K}, P=0.5$ or $50 \mathrm{bar}$, and $\mathrm{C} / \mathrm{O}=0.54$ or 1.1 , with the $\mathrm{C}_{0}-\mathrm{C}_{2}$ and the $\mathrm{C}_{0}-\mathrm{C}_{6}$ scheme. Initial conditions correspond to the thermochemical equilibrium of the bottom level at the profile $T_{500}$, that is, $P=1000$ bar and $T=1742 \mathrm{~K}$ with $\mathrm{C} / \mathrm{O}=0.54$ or 1.1 .

For most species and regardless of the $P, T$, and $\mathrm{C} / \mathrm{O}$ conditions, the kinetic evolution predicted by the two chemical schemes is the same and reaches thermochemical equilibrium. This is demonstrated for $\mathrm{CO}_{2}$ in the first panel of Fig. 1 . Nevertheless, for some hydrocarbon species, we observe a slight difference in the kinetic evolution and sometimes also in the steady state, as can be seen in Fig. 1. These differences are found for species with more than two carbon atoms, which is normal because the $\mathrm{C}_{0}-\mathrm{C}_{2}$ scheme is not made to study these heavy species. It contains $\mathrm{C}_{n} \mathrm{H}_{x}$ species, with $n>2$, only to ensure that species with two or fewer carbon atoms will have a correct behaviour. The abundances and the kinetic evolutions of these heavy species found with the $\mathrm{C}_{0}-\mathrm{C}_{2}$ scheme must not be trusted. Thus, it is expected that we find a difference in evolution for some of these hydrocarbons.

\subsection{Grid of $1 D$ models}

To construct the thermal profiles, we used the analytical model of Parmentier \& Guillot $(2014)^{4}$ that was calibrated to match numerical $P$ - $T$ profiles of solar-composition clear-sky atmospheres by Parmentier et al. (2015). We used the coefficients from Parmentier et al. (2015) and the opacities from Valencia et al. (2013). For simplicity, we did not consider the presence of $\mathrm{TiO}$, which may cause a thermal inversion in hot atmospheres. Moreover, it is still unclear whether there is thermal inversion in hot Jupiters (and whether this is caused by TiO) (e.g. Madhusudhan et al. 2014b; Parmentier et al. 2015). As an illustration, Diamond-Lowe et al. (2014) reanalysed the Spitzer data of HD 209458b and found no evidence for a stratosphere, which contradicts previous studies claiming that the atmosphere of this exoplanet presented a thermal inversion (Burrows et al. 2007; Knutson et al. 2008).

To span a range of conditions relevant to known close-in giant exoplanets, we selected as baselines of our study three thermal profiles with high-altitude atmospheric temperatures of $500 \mathrm{~K}, 1000 \mathrm{~K}$, and $1500 \mathrm{~K}$. These temperature-pressure profiles are shown in Fig. 2. To obtain these profiles, we set the irradiation temperature, $T_{\text {irr }}$, to 784,1522 , and $2303 \mathrm{~K}$. We considered that $\mu=1 / \sqrt{3}$, where $\mu=\cos \theta$ and $\theta$ the inclination of the stellar irradiation with respect to the local vertical direction. This choice allowed us to obtain dayside average profiles. We considered that the planets have a low internal temperature $\left(T_{\text {int }}=100 \mathrm{~K}\right)$ and a gravity of $25 \mathrm{~m} \mathrm{~s}^{-2}$. At the time of the submission of our study, a new version of the analytical model was released. In this version, the user can no longer directly choose the irradiation temperature, but can set the equilibrium temperature, $T_{\text {eq } 0}$, as well as a parameter $f$, which modulates the flux received by the planet. The profiles used in this study correspond approximately to dayside average profiles $(f=0.5)$ of planets with an equilibrium temperature for zero albedo of $T_{\text {eq0 }}=627,1122$, and $1718 \mathrm{~K}$ for the cool, warm, and hot profiles. Since the goal of this study is to compare the $\mathrm{C}_{0}-\mathrm{C}_{2}$ and the $\mathrm{C}_{0}-\mathrm{C}_{6}$ chemical schemes in different conditions, we used the

\footnotetext{
4 https://www-n.oca.eu/parmentier/nongrey/nongrey. html
} 

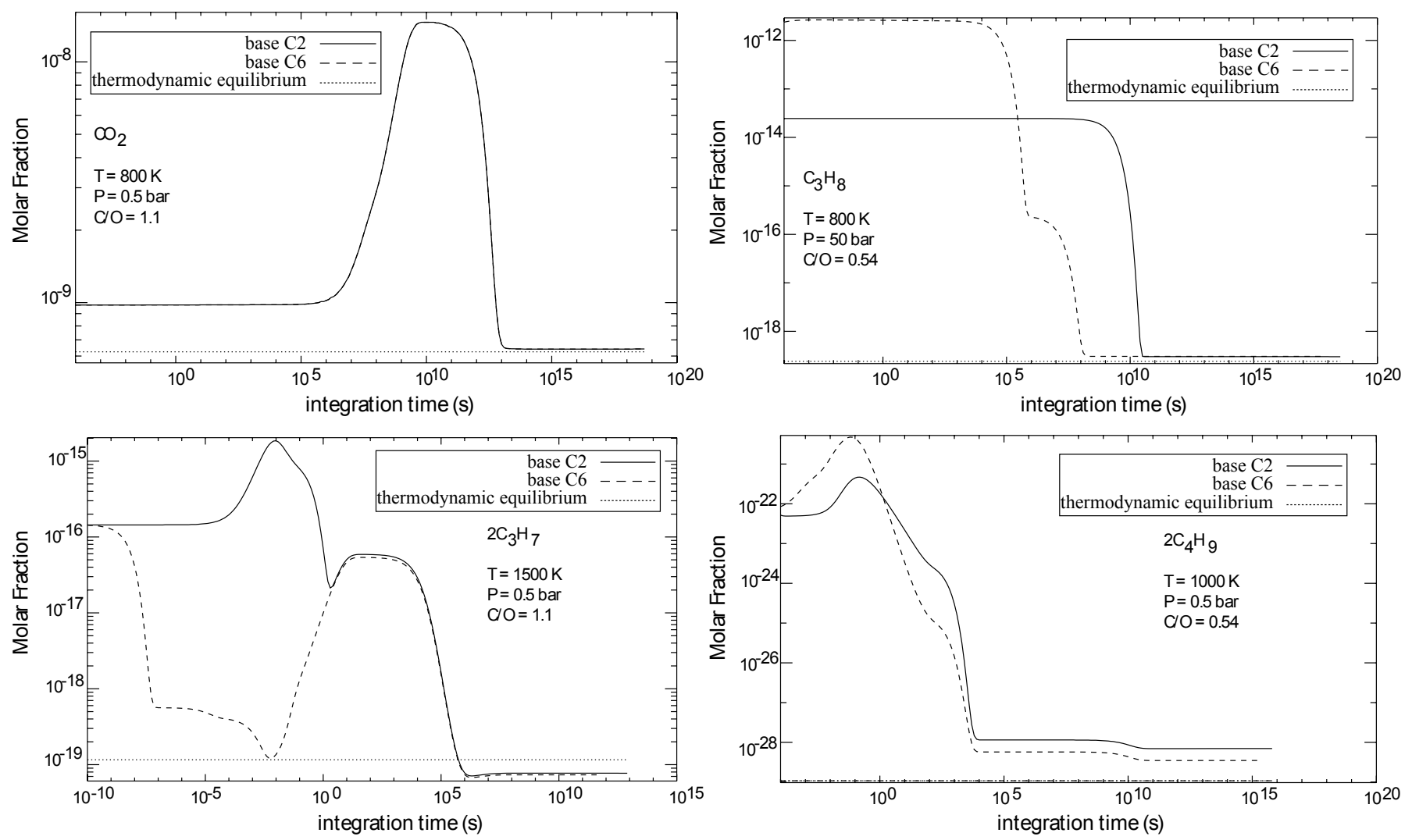

Fig. 1. Kinetic evolution of different species with different pressure, temperature, and $C / O$ ratios, computed with the $0 \mathrm{D}$ model using the $\mathrm{C}_{0}-\mathrm{C}_{2}$ scheme (full line) or the $\mathrm{C}_{0}-\mathrm{C}_{6}$ scheme (dashed line). Kinetic evolutions reach (or evolve toward) thermochemical equilibrium (dotted line).

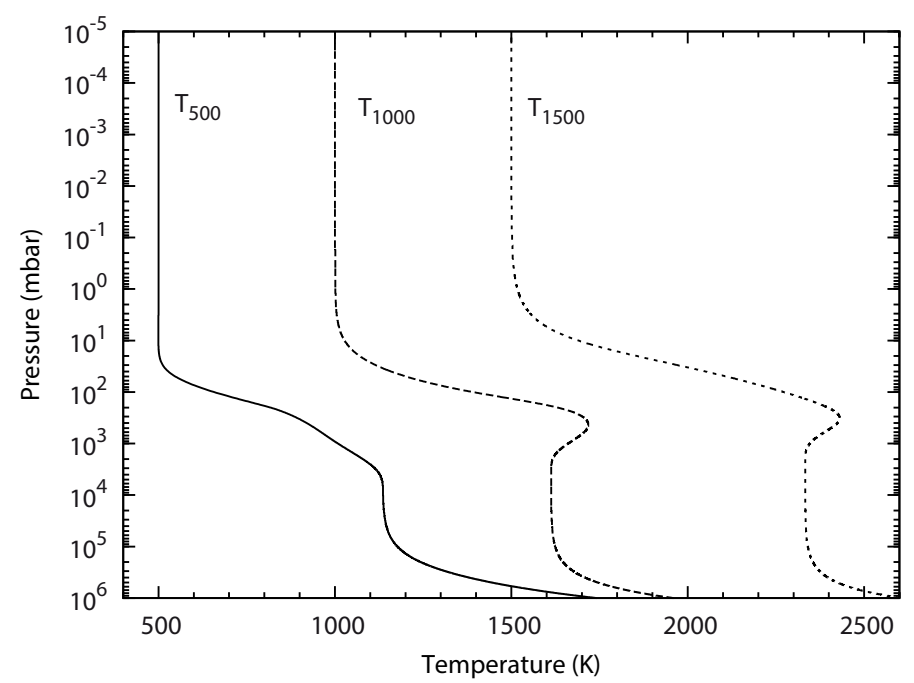

Fig. 2. Vertical profiles of temperature. The cool atmosphere $\left(T_{500}\right)$ has an isothermal part from $\sim 20$ to $10^{-5}$ mbar at $500 \mathrm{~K}$ (full line). The warm atmosphere $\left(T_{1000}\right)$ has an isothermal part from $\sim 2$ to $10^{-5}$ mbar at $1000 \mathrm{~K}$ (dashed line). Finally, the hot atmosphere $\left(T_{1500}\right)$ has an isothermal part from $\sim 0.3$ to $10^{-5}$ mbar at $1500 \mathrm{~K}$ (dotted line).

same thermal profiles when considering a solar and not solar $\mathrm{C} / \mathrm{O}$ ratio, even if the profiles were calculated assuming a solar composition. The $\mathrm{C} / \mathrm{O}$ ratio varies between two values: 0.54 (solar) and 1.1. Finally, we compared the results including or excluding photolysis processes. The different parameters used in the models are summarised in Table 1 with the corresponding
Table 1. Grid of parameters.

\begin{tabular}{lcc}
\hline \hline Parameter & Range of values & Symbol \\
\hline Temperature & Cool atmosphere $(500 \mathrm{~K})$ & $T_{500}$ \\
& Warm atmosphere $(1000 \mathrm{~K})$ & $T_{1000}$ \\
& Hot atmosphere $(1500 \mathrm{~K})$ & $T_{1500}$ \\
\hline C/O ratio & $0.54($ solar $)$ & $\zeta_{0.54}$ \\
& 1.1 & $\zeta_{1.1}$ \\
\hline Stellar UV flux & Irradiation & $F_{\text {On }}$ \\
& No irradiation & $F_{\text {Off }}$ \\
\hline
\end{tabular}

symbols. The planet-star distance of each planet has been adjusted to match their equilibrium temperature. For the cool, warm, and hot profiles, they have been set to $d=0.2196,0.0549$, and $0.0244 \mathrm{AU}$, respectively. Because many uncertainties exist on the vertical mixing acting in exoplanet atmospheres, we used a constant eddy diffusion coefficient, $K_{z z}=10^{8} \mathrm{~cm}^{2} \mathrm{~s}^{-1}$, and did not try to adjust a complex eddy diffusion profile. This value is similar to what has been used or calculated by previous models (i.e. Lewis et al. 2010; Moses et al. 2011; Line et al. 2011; Venot et al. 2013). However, we recall that this value might be too high as pointed out by Parmentier et al. (2013). We did not explore the space of possible values for the eddy diffusion coefficient because it was beyond the scope of this paper. Nevertheless, with a stronger vertical mixing, quenching would occur in deeper layers, and for the $T_{1000}$ and $T_{1500}$ profiles, the $\mathrm{CO} / \mathrm{CH}_{4}$ ratio could become lower than unity in the entire atmosphere (Venot et al. 2014). 


\section{Results}

As can be seen in Figs. 3 and 4, the chemical composition of the atmospheres varies depending on the temperature and the $\mathrm{C} / \mathrm{O}$ ratio. The photodissociations and the chemical scheme used also have an influence. In the following, we comment on these differences and explain them for some species. Indeed, by inspecting the reaction rates, we have identified some formation pathways that occur only in the $\mathrm{C}_{0}-\mathrm{C}_{6}$ chemical scheme and that can explain the departures between the two reactions networks. For species for which the two chemical schemes predict different mixing ratios, we determined from which reactions these compounds were mainly formed. We compared their reaction rates in the two chemical schemes to see which reaction was more efficient in one of the schemes. Then we examined through which reaction the reactants of this latter reaction were formed. We proceeded iteratively until we identified a complete formation pathway. This identification is a preliminary work. Determining the detailed production and destruction pathways of species with precision requires the use of algorithms such as the Pathway Analysis Program (Lehmann 2004; Stock et al. 2012). These algorithms are very powerful, but need to be adapted to chemical schemes as large as our $\mathrm{C}_{0}-\mathrm{C}_{6}$ chemical network. For the clarity of Figs. 3 and 4, we chose to plot only species with significant abundances $\left(>10^{-7}\right)$, but numerous carbon species have an abundance between $10^{-10}$ and $10^{-7}$. We have indicated these species in Table 2.

\subsection{Chemical equilibrium}

At chemical equilibrium there are some differences between the different thermal profiles and $\mathrm{C} / \mathrm{O}$ ratios (see the dotted lines in Fig. 3). Regardless of the $\mathrm{C} / \mathrm{O}$ ratio, the hotter the atmosphere, the higher the $\mathrm{CO} / \mathrm{CH}_{4}$ abundance ratio. $\mathrm{CH}_{4}$ becomes more abundant than $\mathrm{CO}$ at low temperatures, while $\mathrm{CO}$ dominates $\mathrm{CH}_{4}$ at high temperatures. Moreover, the abundance of $\mathrm{H}_{2} \mathrm{O}$ decreases when the temperature increases. We remark that when the $\mathrm{C} / \mathrm{O}$ ratio increases to above unity, then the abundances of carbon-bearing species such as $\mathrm{CH}_{4}, \mathrm{CH}_{3}$, and $\mathrm{HCN}$ increase their abundances significantly. These results agree with previous studies on the effect of the $\mathrm{C} / \mathrm{O}$ ratio on the chemical atmospheric composition (i.e. Madhusudhan et al. 2011b; Madhusudhan 2012; Moses et al. 2013a). When $\mathrm{H}_{2} \mathrm{O}$ is very abundant, $\mathrm{OH}$ behaves similarly to $\mathrm{H}$, but with a smaller amount. However, when the abundance of $\mathrm{H}_{2} \mathrm{O}$ is quite low $\left(\zeta_{1.1}\right.$ for $T_{1000}$ and $T_{1500}$ profiles), the amount of $\mathrm{OH}$ is limited by that of water, and $\mathrm{OH}$ behaves like $\mathrm{H}_{2} \mathrm{O}$. Indeed, in each case tested here, the main reaction that produces $\mathrm{OH}$ is $\mathrm{H}+\mathrm{H}_{2} \mathrm{O} \rightarrow \mathrm{OH}+\mathrm{H}_{2}$, which means that $\mathrm{OH}$ is limited by the reactant of the less abundant species.

\subsection{Without photodissociation}

The chemical compositions given by the $\mathrm{C}_{0}-\mathrm{C}_{2}$ and the $\mathrm{C}_{0^{-}}$ $\mathrm{C}_{6}$ chemical schemes are identical (considering species that are present in both networks) for all thermal profiles and the two $\mathrm{C} / \mathrm{O}$ ratios when photodissociation is omitted. The only departure between the two schemes concerns some $\mathrm{C}_{n>2} \mathrm{H}_{x}$ species. As we explained in Sect. 2.2, the $\mathrm{C}_{0}-\mathrm{C}_{2}$ contains species with three or four carbon atoms to correctly describe the kinetics of the species with two carbon atoms, but the kinetic behaviour of these heavier compounds must not be trusted. Thus, it is expected that the $\mathrm{C}_{0}-\mathrm{C}_{6}$ scheme predicts a different behaviour for these hydrocarbons. Nevertheless, these small departures do not affect the abundances of the main species represented in Fig. 3.

The quenching level is different depending on the thermal profile. Logically, the cooler the profile, the deeper quenching occurs in the atmosphere. For $T_{500}$, quenching occurs between $10^{5}$ and $10^{4}$ mbar, depending on the molecule, whereas for $T_{1500}$, it occurs much higher in the atmosphere, at about 20 mbar.

\subsection{With photodissociation}

\subsubsection{Cool $\left(T_{500}\right)$ profile}

For $T_{500}$, there are differences between the two chemical schemes, both for the solar $\mathrm{C} / \mathrm{O}$ ratio and for the carbon-rich case. In both cases, important carbon species such as $\mathrm{CO}$ and $\mathrm{C}_{2} \mathrm{H}_{2}$ are destroyed in the upper atmosphere by photolysis. With the $\mathrm{C}_{0}-\mathrm{C}_{6}$ scheme, these species are destroyed to a larger extent than with the $\mathrm{C}_{0}-\mathrm{C}_{2}$ scheme, and we found that the "missing" carbon is placed in $\mathrm{CC}_{6} \mathrm{H}_{8}$ through the following chemical pathway, starting with the photodissociation of $\mathrm{CO}$ :

$$
\begin{aligned}
\mathrm{CO}+\mathrm{h} v & \longrightarrow \mathrm{C}+\mathrm{O}\left({ }^{3} \mathrm{P}\right) \\
\mathrm{C}+\mathrm{H}_{2} & \longrightarrow \mathrm{CH}+\mathrm{H} \\
\mathrm{CH}+\mathrm{H}_{2} & \longrightarrow{ }^{3} \mathrm{CH}_{2}+\mathrm{H} \\
{ }^{3} \mathrm{CH}_{2}+\mathrm{C} & \longrightarrow \mathrm{C}_{2} \mathrm{H}+\mathrm{H} \\
\mathrm{C}_{2} \mathrm{H}+\mathrm{H} & \longrightarrow \mathrm{C}_{2} \mathrm{H}_{2} \\
2 \mathrm{C}_{2} \mathrm{H}_{2} & \longrightarrow \mathrm{nC}_{4} \mathrm{H}_{3}+\mathrm{H} \\
\mathrm{nC}_{4} \mathrm{H}_{3}+\mathrm{C}_{2} \mathrm{H}_{2} & \longrightarrow \mathrm{C}_{6} \mathrm{H}_{5} \\
\mathrm{lC}_{6} \mathrm{H}_{5} & \longrightarrow \mathrm{cC}_{6} \mathrm{H}_{5} \\
\mathrm{cC}_{6} \mathrm{H}_{5}+\mathrm{H} & \longrightarrow \mathrm{cC}_{6} \mathrm{H}_{6} \\
\mathrm{cC}_{6} \mathrm{H}_{6}+\mathrm{H} & \longrightarrow \mathrm{cC}_{6} \mathrm{H}_{7} \\
\mathrm{cC}_{6} \mathrm{H}_{7}+\mathrm{H} & \longrightarrow \mathrm{cC}_{6} \mathrm{H}_{8} \\
\hline \mathrm{CO}+2 \mathrm{C}_{2} \mathrm{H}_{2}+2 \mathrm{H}_{2}+\mathrm{C} & \longrightarrow \mathrm{cC}_{6} \mathrm{H}_{8}+\mathrm{O}\left({ }^{3} \mathrm{P}\right)
\end{aligned}
$$

Since it involved heavy hydrocarbons, it can only occur for the $\mathrm{C}_{0}-\mathrm{C}_{6}$ scheme.

\subsubsection{Warm $\left(T_{1000}\right)$ and hot $\left(T_{1500}\right)$ profiles}

As seen in Fig. 4, for any of these two $P$ - $T$ profiles there is no difference between the results given by the two chemical schemes when the $\mathrm{C} / \mathrm{O}$ ratio is solar, but there are some differences in the upper atmosphere when the $\mathrm{C} / \mathrm{O}$ ratio is $>1$. First, we focus on $\mathrm{C} / \mathrm{O}=1.1$.

In the warm and hot profiles, we found that in contrast to the cool profile, $\mathrm{cC}_{6} \mathrm{H}_{8}$ is unimportant. We discovered that this heavy species is not abundant when the temperature is high because of the reaction $\mathrm{nC}_{4} \mathrm{H}_{3}+\mathrm{C}_{2} \mathrm{H}_{2} \longrightarrow 1 \mathrm{C}_{6} \mathrm{H}_{5}$, which is the limiting reaction in the mechanism identified above for the production of $\mathrm{cC}_{6} \mathrm{H}_{8}$. The equilibrium constant of this reaction (represented in Fig. 5) was calculated as a function of temperature. At low temperature, the equilibrium constant is high so $k_{f}(T) \gg k_{r}(T)$, thus, the addition of $\mathrm{nC}_{4} \mathrm{H}_{3}$ with $\mathrm{C}_{2} \mathrm{H}_{2}$ is favoured to form $\mathrm{lC}_{6} \mathrm{H}_{5}$ (and then $\mathrm{cC}_{6} \mathrm{H}_{8}$ ). At high temperature, the equilibrium constant is very low, so the reverse reaction is predominant. The destruction of $\mathrm{CC}_{6} \mathrm{H}_{5}$ is favoured. As a consequence, the concentration of $\mathrm{cC}_{6} \mathrm{H}_{8}$ is lower.

The main species that show differences in their abundances when using either the $\mathrm{C}_{0}-\mathrm{C}_{2}$ or $\mathrm{C}_{0}-\mathrm{C}_{6}$ schemes are $\mathrm{CH}_{3}, \mathrm{CH}_{4}$, $\mathrm{H}_{2} \mathrm{O}$, and $\mathrm{CO}_{2}$, which are more abundant when using the $\mathrm{C}_{0}-\mathrm{C}_{6}$ scheme than the $\mathrm{C}_{0}-\mathrm{C}_{2}$ scheme. $\mathrm{C}_{2} \mathrm{H}_{2}$ and $\mathrm{H}$ are also slightly 
Table 2. Highest abundances of some hydrocarbon species not plotted in Fig. 4, but with an abundance higher than $10^{-10}$.

\begin{tabular}{|c|c|c|c|c|c|c|}
\hline Species & $T_{1500} \zeta_{0.54}$ & $T_{1500} \zeta_{1.1}$ & $T_{1000} \zeta_{0.54}$ & $T_{1000} \zeta_{1.1}$ & $T_{500} \zeta_{0.54}$ & $T_{500} \zeta_{1.1}$ \\
\hline $\mathrm{CH}$ & $<10^{-10}$ & $4.4 \times 10^{-8}\left(3 \times 10^{-3}\right)$ & $<10^{-10}$ & $2.0 \times 10^{-9}\left(9 \times 10^{-4}\right)$ & $<10^{-10}$ & $1.2 \times 10^{-10}\left(2 \times 10^{-3}\right)$ \\
\hline${ }^{1} \mathrm{CH}_{2}$ & $1.7 \times 10^{-9}\left(10^{6}\right)$ & $7.0 \times 10^{-9}\left(3 \times 10^{2}\right)$ & $<10^{-10}$ & $<10^{-10}$ & $<10^{-10}$ & $<10^{-10}$ \\
\hline${ }^{3} \mathrm{CH}_{2}$ & $2.4 \times 10^{-8}\left(10^{6}\right)$ & $1.1 \times 10^{-7}\left(3 \times 10^{2}\right)$ & $<10^{-10}$ & $8.3 \times 10^{-9}\left(8 \times 10^{-3}\right)$ & $2.1 \times 10^{-9}\left(3 \times 10^{-3}\right)$ & $4.6 \times 10^{-9}\left(3 \times 10^{-3}\right)$ \\
\hline $\mathrm{HCO}$ & $2.5 \times 10^{-8}\left(10^{6}\right)$ & $4.3 \times 10^{-8}\left(10^{6}\right)$ & $1.8 \times 10^{-10}\left(10^{6}\right)$ & $3.4 \times 10^{-10}\left(10^{6}\right)$ & $<10^{-10}$ & $<10^{-10}$ \\
\hline $\mathrm{H}_{2} \mathrm{CO}$ & $7.9 \times 10^{-8}\left(10^{6}\right)$ & $1.4 \times 10^{-7}\left(10^{6}\right)$ & $5.7 \times 10^{-9}\left(10^{6}\right)$ & $1.1 \times 10^{-8}\left(10^{6}\right)$ & $1.1 \times 10^{-9}\left(2 \times 10^{-3}\right)$ & $2.8 \times 10^{-9}\left(2 \times 10^{-3}\right)$ \\
\hline $\mathrm{CH}_{2} \mathrm{OH}$ & $1.2 \times 10^{-10}\left(10^{6}\right)$ & $2.0 \times 10^{-10}\left(10^{6}\right)$ & $<10^{-10}$ & $<10^{-10}$ & $<10^{-10}$ & \\
\hline $\mathrm{CH}_{3} \mathrm{OH}$ & $1.6 \times 10^{-9}\left(10^{6}\right)$ & $2.7 \times 10^{-10}\left(10^{6}\right)$ & $4.5 \times 10^{-10}\left(10^{6}\right)$ & $8.9 \times 10^{-10}\left(10^{6}\right)$ & $1.8 \times 10^{-10}\left(10^{6}\right)$ & $3.6 \times 10^{-10}\left(10^{6}\right)$ \\
\hline $\mathrm{C}_{2} \mathrm{H}$ & $<10^{-10}$ & $1.6 \times 10^{-7}\left(2 \times 10^{2}\right)$ & $<10^{-10}$ & $5.0 \times 10^{-9}\left(9 \times 10^{-4}\right)$ & $<10^{-10}$ & $<10^{-10}$ \\
\hline $\mathrm{CH}_{2} \mathrm{CO}$ & $1.9 \times 10^{-10}\left(10^{6}\right)$ & $6.8 \times 10^{-10}\left(10^{6}\right)$ & $<10^{-10}$ & $<10^{-10}$ & $<10^{-10}$ & $<10^{-10}$ \\
\hline $\mathrm{CH}_{2} \mathrm{CHO}$ & $<10^{-10}$ & $<10^{-10}$ & $<10^{-10}$ & $<10^{-10}$ & $6.5 \times 10^{-10}\left(2 \times 10^{-3}\right)$ & $1.6 \times 10^{-9}\left(2 \times 10^{-3}\right)$ \\
\hline $\mathrm{C}_{2} \mathrm{H}_{3}$ & $1.1 \times 10^{-9}\left(10^{6}\right)$ & $4.7 \times 10^{-9}\left(10^{6}\right)$ & $<10^{-10}$ & $2.1 \times 10^{-10}\left(7 \times 10^{-2}\right)$ & $<10^{-10}$ & $<10^{-10}$ \\
\hline $\mathrm{C}_{2} \mathrm{H}_{4}$ & $8.2 \times 10^{-8}\left(10^{6}\right)$ & $3.6 \times 10^{-7}\left(10^{6}\right)$ & $8.1 \times 10^{-9}\left(10^{6}\right)$ & $7.1 \times 10^{-8}\left(9 \times 10^{-2}\right)$ & $2.0 \times 10^{-7}\left(5 \times 10^{-3}\right)$ & $7.5 \times 10^{-7}\left(5 \times 10^{-3}\right)$ \\
\hline $\mathrm{C}_{2} \mathrm{H}_{5}$ & $8.1 \times 10^{-10}\left(10^{6}\right)$ & $3.4 \times 10^{-9}\left(10^{6}\right)$ & $<10^{-10}$ & $1.3 \times 10^{-10}\left(10^{6}\right)$ & $<10^{-10}$ & $3.6 \times 10^{-10}\left(2 \times 10^{-1}\right)$ \\
\hline $\mathrm{C}_{2} \mathrm{H}_{6}$ & $5.0 \times 10^{-9}\left(10^{6}\right)$ & $2.1 \times 10^{-8}\left(10^{6}\right)$ & $4.1 \times 10^{-9}\left(10^{6}\right)$ & $1.6 \times 10^{-8}\left(10^{6}\right)$ & $6.2 \times 10^{-7}\left(2 \times 10^{-1}\right)$ & $2.3 \times 10^{-6}\left(2 \times 10^{-1}\right)$ \\
\hline $\mathrm{aC}_{3} \mathrm{H}_{4}$ & $<10^{-10}$ & $<10^{-10}$ & $<10^{-10}$ & $<10^{-10}$ & $5.5 \times 10^{-9}\left(3 \times 10^{-3}\right)$ & $1.8 \times 10^{-8}\left(2 \times 10^{-3}\right)$ \\
\hline $\mathrm{pC}_{3} \mathrm{H}_{4}$ & $<10^{-10}$ & $1.6 \times 10^{-10}\left(10^{6}\right)$ & $<10^{-10}$ & $<10^{-10}$ & $1.1 \times 10^{-9}\left(4 \times 10^{-3}\right)$ & $3.0 \times 10^{-9}\left(4 \times 10^{-3}\right)$ \\
\hline $\mathrm{C}_{3} \mathrm{H}_{2}$ & $<10^{-10}$ & $6.1 \times 10^{-9}\left(2 \times 10^{-2}\right)$ & $<10^{-10}$ & $1.7 \times 10^{-9}\left(6 \times 10^{-3}\right)$ & $5.3 \times 10^{-10}\left(2 \times 10^{-3}\right)$ & $1.1 \times 10^{-9}\left(2 \times 10^{-3}\right)$ \\
\hline $\mathrm{C}_{3} \mathrm{H}_{3}$ & $<10^{-10}$ & $2.2 \times 10^{-9}\left(2 \times 10^{-2}\right)$ & $<10^{-10}$ & $7.3 \times 10^{-9}\left(6 \times 10^{-3}\right)$ & $2.5 \times 10^{-9}\left(2 \times 10^{-3}\right)$ & $5.1 \times 10^{-9}\left(2 \times 10^{-3}\right)$ \\
\hline $\mathrm{C}_{2} \mathrm{H}_{3} \mathrm{CHO}$ & $<10^{-10}$ & $<10^{-10}$ & $<10^{-10}$ & $<10^{-10}$ & $3.4 \times 10^{-10}\left(1 \times 10^{-3}\right)$ & $8.1 \times 10^{-10}\left(1 \times 10^{-3}\right)$ \\
\hline $2 \mathrm{C}_{3} \mathrm{H}_{5}$ & $<10^{-10}$ & $<10^{-10}$ & $<10^{-10}$ & $<10^{-10}$ & $2.6 \times 10^{-10}\left(8 \times 10^{-4}\right)$ & $3.5 \times 10^{-10}\left(8 \times 10^{-4}\right)$ \\
\hline $\mathrm{C}_{3} \mathrm{H}_{8}$ & $<10^{-10}$ & $<10^{-10}$ & $<10^{-10}$ & $<10^{-10}$ & $4.6 \times 10^{-9}\left(1 \times 10^{-3}\right)$ & $2.9 \times 10^{-8}\left(2 \times 10^{-1}\right)$ \\
\hline $\mathrm{C}_{4} \mathrm{H}_{2}$ & $<10^{-10}$ & $1.1 \times 10^{-10}\left(10^{2}\right)$ & $<10^{-10}$ & $1.5 \times 10^{-9}\left(5 \times 10^{-3}\right)$ & $3.6 \times 10^{-9}\left(2 \times 10^{-3}\right)$ & $6.7 \times 10^{-9}\left(10^{-3}\right)$ \\
\hline $\mathrm{C}_{4} \mathrm{H}_{4} \mathrm{O}$ & $<10^{-10}$ & $<10^{-10}$ & $<10^{-10}$ & $<10^{-10}$ & $<10^{-10}$ & $1.4 \times 10^{-10}\left(1 \times 10^{-3}\right)$ \\
\hline $1 \mathrm{C}_{4} \mathrm{H}_{6}$ & $<10^{-10}$ & $<10^{-10}$ & $<10^{-10}$ & $<10^{-10}$ & $2.0 \times 10^{-10}\left(3 \times 10^{-3}\right)$ & $6.9 \times 10^{-10}\left(2 \times 10^{-3}\right)$ \\
\hline $\mathrm{iC}_{4} \mathrm{H}_{8}$ & $<10^{-10}$ & $<10^{-10}$ & $<10^{-10}$ & $<10^{-10}$ & $<10^{-10}$ & $1.4 \times 10^{-10}\left(3 \times 10^{-3}\right)$ \\
\hline $\mathrm{C}_{4} \mathrm{H}_{10}$ & $<10^{-10}$ & $<10^{-10}$ & $<10^{-10}$ & $<10^{-10}$ & $<10^{-10}$ & $4.4 \times 10^{-10}\left(2 \times 10^{-1}\right)$ \\
\hline $\mathrm{cC}_{5} \mathrm{H}_{6}$ & $<10^{-10}$ & $<10^{-10}$ & $<10^{-10}$ & $3.1 \times 10^{-10}\left(3 \times 10^{-2}\right)$ & $1.3 \times 10^{-10}\left(2 \times 10^{-3}\right)$ & $3.6 \times 10^{-10}\left(10^{-3}\right)$ \\
\hline $1 \mathrm{C}_{6} \mathrm{H}_{4}$ & $<10^{-10}$ & $<10^{-10}$ & $<10^{-10}$ & $<10^{-10}$ & $2.6 \times 10^{-8}\left(3 \times 10^{-3}\right)$ & $8.4 \times 10^{-8}\left(3 \times 10^{-3}\right)$ \\
\hline $\mathrm{cC}_{6} \mathrm{H}_{6}$ & $<10^{-10}$ & $<10^{-10}$ & $<10^{-10}$ & $<10^{-10}$ & $1.1 \times 10^{-9}\left(2 \times 10^{-3}\right)$ & $3.1 \times 10^{-9}\left(2 \times 10^{-3}\right)$ \\
\hline $\mathrm{cC}_{6} \mathrm{H}_{5} \mathrm{OH}$ & $<10^{-10}$ & $<10^{-10}$ & $<10^{-10}$ & $<10^{-10}$ & $2.2 \times 10^{-8}\left(3 \times 10^{-3}\right)$ & $7.6 \times 10^{-8}\left(3 \times 10^{-3}\right)$ \\
\hline
\end{tabular}

Notes. These mixing ratios are obtained using the $\mathrm{C}_{0}-\mathrm{C}_{6}$ scheme with the six models including photodissociations. The level pressure (in mbar) at which these abundances are reached is noted between parenthesis. Hydrocarbons that are not indicated in this table have an abundance always lower than $10^{-10}$.

affected and are less abundant for the $\mathrm{C}_{0}-\mathrm{C}_{6}$ scheme. This occurs between 10 and $10^{-3}$ mbar for $T_{1500}$, and between 0.3 and $10^{-4}$ mbar for $T_{1000}$. We present for each of these species the mechanisms we identified to explain these departures between the two chemical networks.

Methyl radical $\left(\mathrm{CH}_{3}\right)$ : For $\mathrm{CH}_{3}$, we found that acetylene $\left(\mathrm{C}_{2} \mathrm{H}_{2}\right)$ is responsible for the higher mixing ratio obtained with the $\mathrm{C}_{0}-\mathrm{C}_{6}$ scheme. $\mathrm{C}_{2} \mathrm{H}_{2}$ forms $\mathrm{CH}_{3}$ through the following chemical pathway, involving heavy hydrocarbons that are only present in the $\mathrm{C}_{0}-\mathrm{C}_{6}$ scheme:

$$
\begin{array}{rll}
\mathrm{C}_{2} \mathrm{H}_{2}+\mathrm{H} & \longrightarrow \mathrm{C}_{2} \mathrm{H}_{3} \\
\mathrm{C}_{2} \mathrm{H}_{3}+\mathrm{H}_{2} & \longrightarrow \mathrm{C}_{2} \mathrm{H}_{4}+\mathrm{H} \\
\mathrm{C}_{2} \mathrm{H}_{4}+\mathrm{H} & \longrightarrow \mathrm{C}_{2} \mathrm{H}_{5} \\
\mathrm{C}_{2} \mathrm{H}_{5}+\mathrm{H} & \longrightarrow 2 \mathrm{CH}_{3} \\
\hline \mathrm{C}_{2} \mathrm{H}_{2}+2 \mathrm{H}+\mathrm{H}_{2} & \longrightarrow 2 \mathrm{CH}_{3} .
\end{array}
$$

This explains the lower abundance of $\mathrm{C}_{2} \mathrm{H}_{2}$ when the $\mathrm{C}_{0}-\mathrm{C}_{6}$ scheme is used.
Methane $\left(\mathrm{CH}_{4}\right)$ : Methane is mainly formed (at 99\%) via the reaction $\mathrm{CH}_{3}+\mathrm{H}_{2} \longrightarrow \mathrm{CH}_{4}+\mathrm{H}$, so its abundance is linked to that of $\mathrm{CH}_{3}$. Because $\mathrm{CH}_{3}$ is more abundant for the $\mathrm{C}_{0}-\mathrm{C}_{6}$ scheme, there is more methane when using this network.

Water $\left(\mathrm{H}_{2} \mathrm{O}\right)$ and carbon dioxide $\left(\mathrm{CO}_{2}\right)$ : For the $T_{1000}$ and $T_{1500}$ profiles, $\mathrm{H}_{2} \mathrm{O}$ and $\mathrm{CO}_{2}$ behave in the same way. These two species are in equilibrium according to the reaction scheme previously found by Moses et al. (2011) in hot Jupiters:

$$
\begin{aligned}
\mathrm{H}_{2} \mathrm{O}+\mathrm{H} & \longleftrightarrow \mathrm{OH}+\mathrm{H}_{2} \\
\mathrm{CO}+\mathrm{OH} & \longleftrightarrow \mathrm{CO}_{2}+\mathrm{H} \\
\hline \mathrm{H}_{2} \mathrm{O}+\mathrm{CO} & \longleftrightarrow \mathrm{CO}_{2}+\mathrm{H} .
\end{aligned}
$$

We remark that $\mathrm{H}_{2} \mathrm{O}$ and $\mathrm{CO}_{2}$ have different abundances depending on the chemical scheme. These departures are found at $\sim 2 \times 10^{-3}$ mbar for $T_{1000}$ and around $10^{-1}$ mbar for $T_{1500}$. In both cases, the two species are more abundant for the $\mathrm{C}_{0}-\mathrm{C}_{6}$ than for the $\mathrm{C}_{0}-\mathrm{C}_{2}$ scheme. Identifying why there is more water when using the $\mathrm{C}_{0}-\mathrm{C}_{6}$ scheme is very difficult because $\mathrm{H}_{2} \mathrm{O}$ 
O. Venot et al.: New chemical scheme for studying carbon-rich exoplanet atmospheres
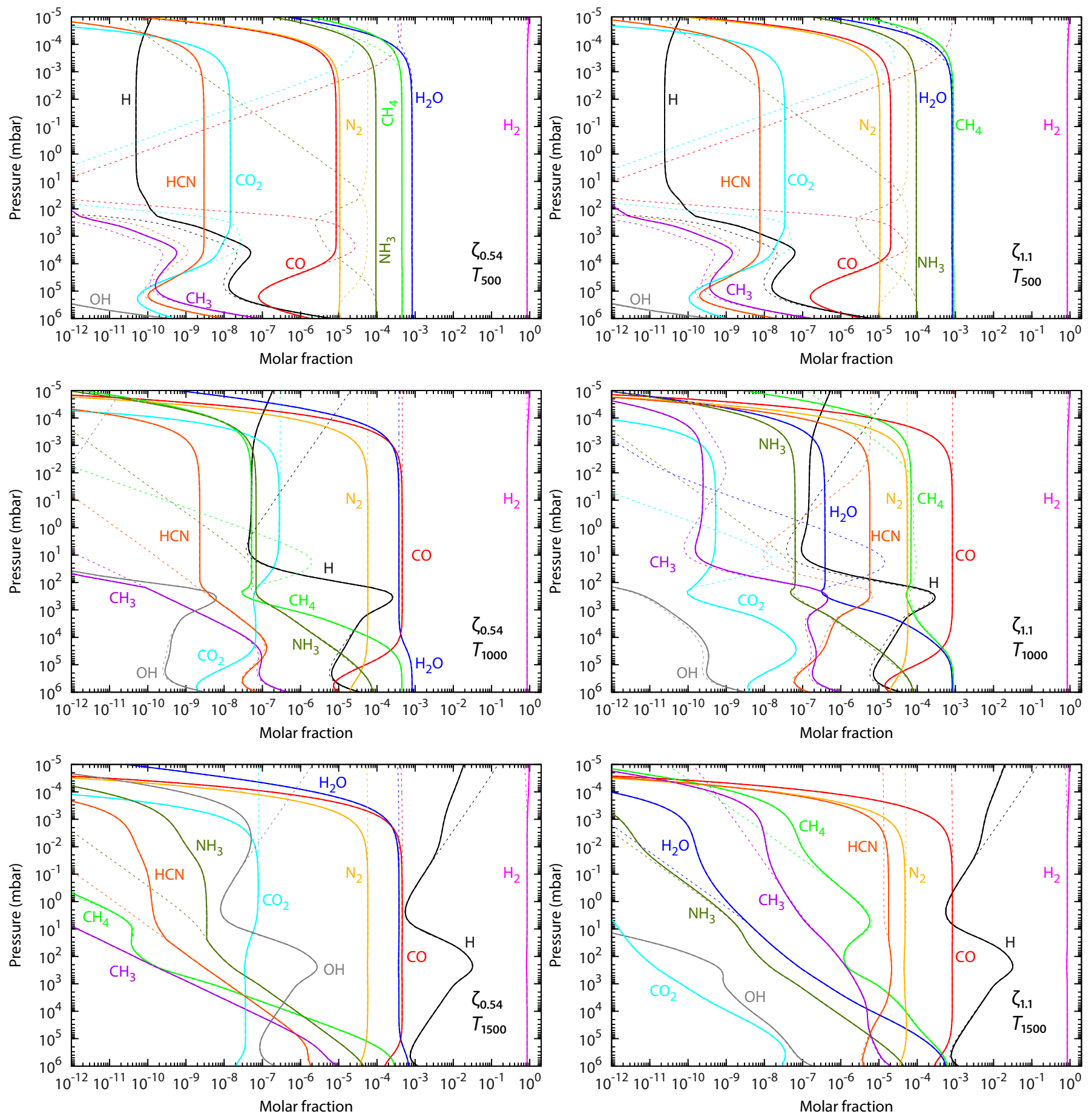

Fig. 3. Vertical abundance profiles for the cool (up), warm (middle), and hot (bottom) thermal profiles, with the $\mathrm{C} / \mathrm{O}$ ratio solar $(l e f t)$ and $\mathrm{C} / \mathrm{O}=1.1$ (right). The chemical compositions are calculated with the $\mathrm{C}_{0}-\mathrm{C}_{2}$ scheme (dashed line) and the $\mathrm{C}_{0}-\mathrm{C}_{6}$ scheme (solid line), without photodissociation. Dashed and solid lines overlap, so that the dashed lines are obscured. The chemical equilibrium (dotted line) is also represented.

is involved in very many reactions. Nevertheless, we found a possible explanation: in both chemical schemes, the main reaction (at $\sim 99 \%$ ) producing water is $\mathrm{OH}+\mathrm{H}_{2} \longrightarrow \mathrm{H}_{2} \mathrm{O}+\mathrm{H}$, but the reaction $\mathrm{OH}+\mathrm{CH}_{4} \longrightarrow \mathrm{CH}_{3}+\mathrm{H}_{2} \mathrm{O}$ also participates in the formation of water. The contribution of this reaction is two orders of magnitude stronger for the $\mathrm{C}_{0}-\mathrm{C}_{6}$ scheme than for $\mathrm{C}_{0}-\mathrm{C}_{2}$. Moreover, methane is $\sim 1000$ times more abundant at this level for the $\mathrm{C}_{0}-\mathrm{C}_{6}$ scheme. This can probably explain the higher mixing ratio of $\mathrm{H}_{2} \mathrm{O}$ obtained for the $\mathrm{C}_{0}-\mathrm{C}_{6}$ scheme. As we said at the beginning of Sect. 3, this hypothesis needs to be confirmed with a specific algorithm, and this will be the subject of a more detailed study. The higher amount of $\mathrm{CO}_{2}$ is then a natural consequence of the equilibrium between the two species.

Acetylene $\left(\mathrm{C}_{2} \mathrm{H}_{2}\right)$ : We have shown that $\mathrm{C}_{2} \mathrm{H}_{2}$ is an important species in atmospheres with a high $\mathrm{C} / \mathrm{O}$ ratio. This species is involved in the formation of $\mathrm{CH}_{3}$ and so is indirectly involved in the formation of $\mathrm{CH}_{4}, \mathrm{H}_{2} \mathrm{O}$, and $\mathrm{CO}_{2}$. We can see in Fig. 4 that acetylene is a species with a globally high abundance in the 

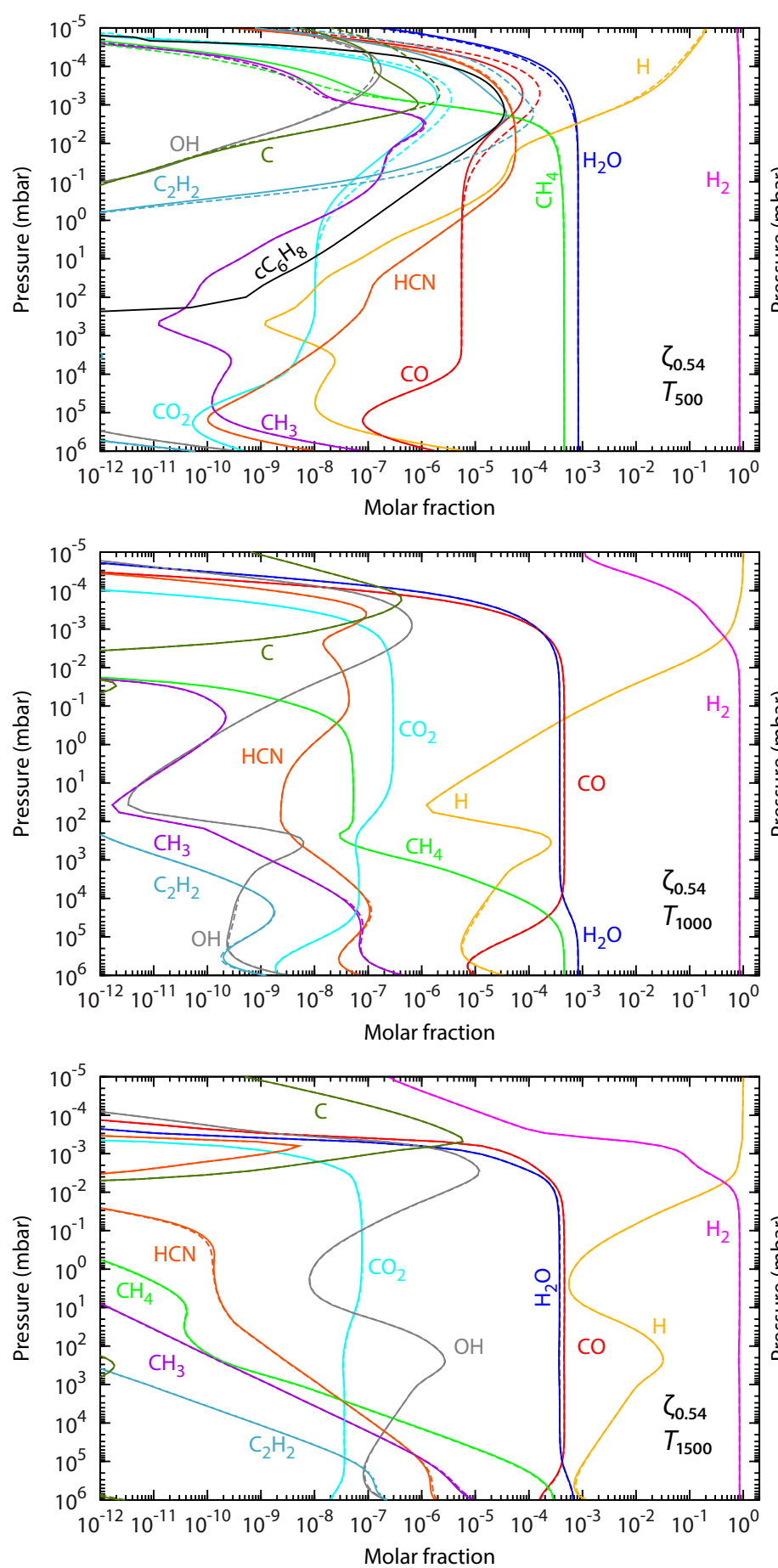
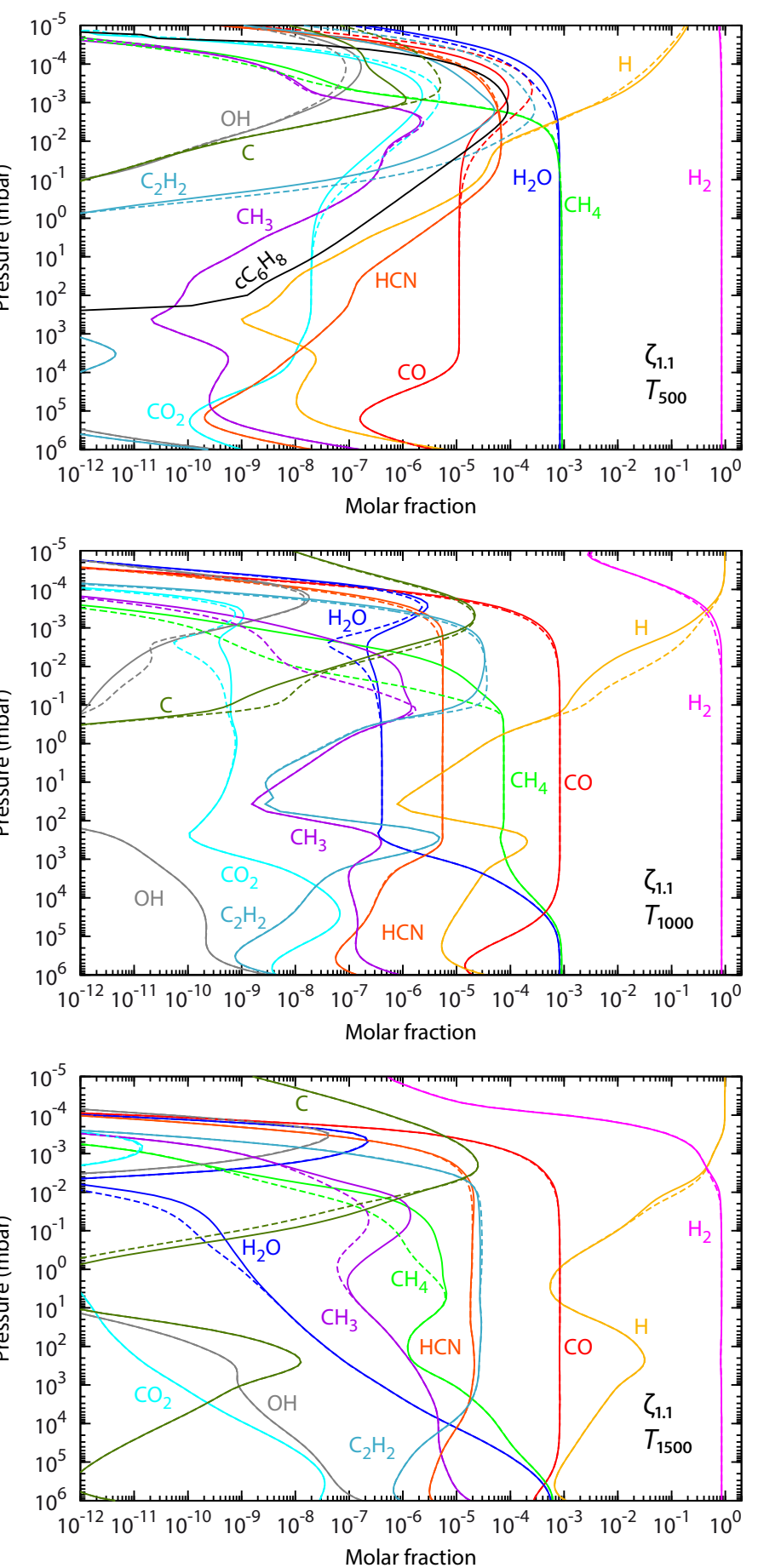

Fig. 4. Vertical abundance profiles for the cool (up), warm (middle), and hot (bottom) thermal profiles, with the $\mathrm{C} / \mathrm{O}$ ratio solar (left) and $\mathrm{C} / \mathrm{O}=1.1$ (right). The chemical compositions are calculated with the $\mathrm{C}_{0}-\mathrm{C}_{2}$ scheme (dashed line) and the $\mathrm{C}_{0}-\mathrm{C}_{6}$ scheme (solid line), with photodissociation.

atmosphere for the $\zeta_{1.1}$ cases. But if we compare this with the $\zeta_{0.54}$ cases, we realise that this is different when the $\mathrm{C} / \mathrm{O}$ ratio is solar. In these cases, $\mathrm{C}_{2} \mathrm{H}_{2}$ is not abundant in the atmosphere. Furthermore, $\mathrm{C}_{2} \mathrm{H}_{2}$ is also abundant in the $T_{500}$ cases in the upper atmosphere because of photochemistry.

As Fig. 6 shows it, for $T \geqslant 800 \mathrm{~K}$, there is a difference of several orders of magnitude between the abundance of $\mathrm{C}_{2} \mathrm{H}_{2}$ predicted by thermochemical equilibrium when considering a gas mixture with a solar $\mathrm{C} / \mathrm{O}$ ratio or equal to 1.1 . The low abundance of $\mathrm{C}_{2} \mathrm{H}_{2}$ in the $\zeta_{0.54}$ cases explains why there is no departure between the results obtained for the two chemical schemes. If there is no $\mathrm{C}_{2} \mathrm{H}_{2}$, the chemical pathways leading to the formation of $\mathrm{CH}_{3}$ identified in the paragraph $\left(\mathrm{CH}_{3}\right)$ cannot occur. $\mathrm{CH}_{3}, \mathrm{CH}_{4}, \mathrm{H}_{2} \mathrm{O}$, and $\mathrm{CO}_{2}$ will remain at the same abundances as were found for the $\mathrm{C}_{0}-\mathrm{C}_{2}$ scheme. This indicates the important role of acetylene in the output of the chemical network calculations.

\section{Spectra}

To determine whether the differences in abundances obtained using the two chemical schemes have an impact on the spectra, we computed the synthetic spectra corresponding to the 12 atmospheric compositions using the code described in 
O. Venot et al.: New chemical scheme for studying carbon-rich exoplanet atmospheres

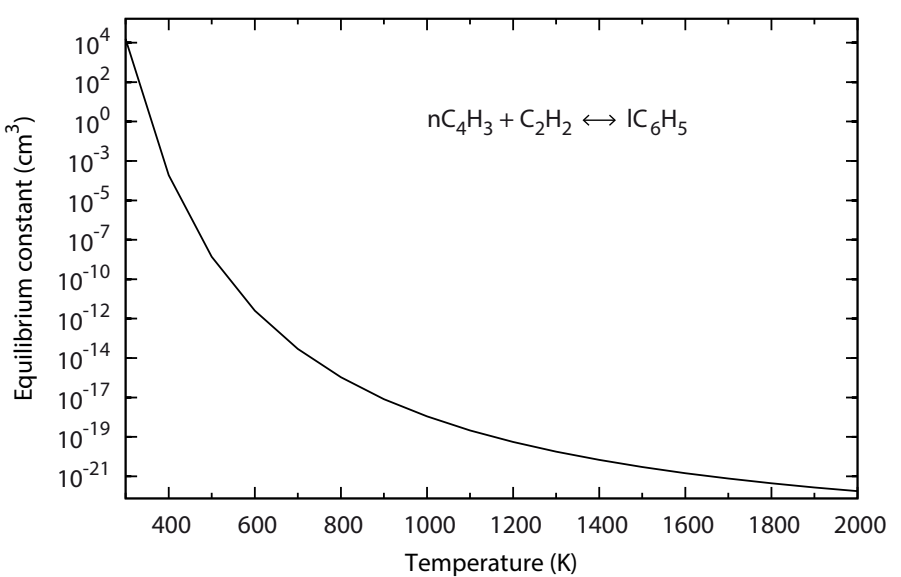

Fig. 5. Equilibrium constant of the reaction $\mathrm{nC}_{4} \mathrm{H}_{3}+\mathrm{C}_{2} \mathrm{H}_{2} \longleftrightarrow 1 \mathrm{C}_{6} \mathrm{H}_{5}$ as a function of temperature. Because the number of reactants and products is different, the equilibrium constant is not dimensionless.

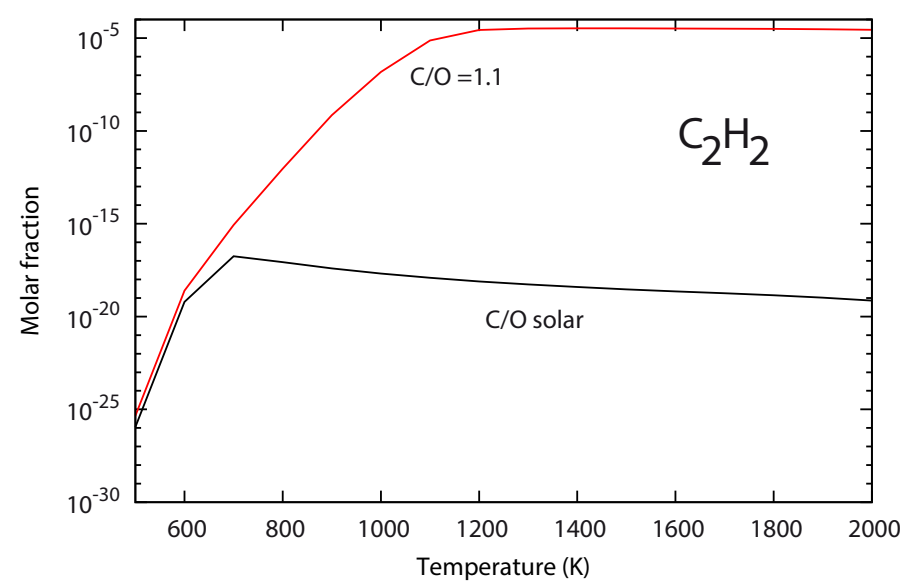

Fig. 6. Abundance of acetylene at the thermochemical equilibrium as a function of temperature. Two cases are represented: $\mathrm{C} / \mathrm{O}=$ solar (black) and $\mathrm{C} / \mathrm{O}=1.1$ (red).

Agúndez et al. (2014a). For this study, the opacities of $\mathrm{C}_{2} \mathrm{H}_{2}$, $\mathrm{C}_{2} \mathrm{H}_{4}$, and $\mathrm{C}_{2} \mathrm{H}_{6}$ compiled in HITRAN2012 (Rothman et al. 2013) were added because these $\mathrm{C}$-species can potentially be important in $\mathrm{C}$-rich atmospheres under certain conditions. Nevertheless, in the different models we have tested, $\mathrm{C}_{2} \mathrm{H}_{4}$ and $\mathrm{C}_{2} \mathrm{H}_{6}$ are not sufficiently abundant (always lower than $10^{-6}$ ) to affect the synthetic spectra. Note that the opacities of $\mathrm{cC}_{6} \mathrm{H}_{8}$ and $\mathrm{CH}_{3}$ are not included because these data are not known, but they could have an important influence on the synthetic spectra and should be added as soon as they are available. For the same reason, opacities of other $\mathrm{C}_{n>2} \mathrm{H}_{x}$ species are not included neither. Nevertheless, in view of their low abundances (see Table 2), they would probably not influence the synthetic spectra. We present in this section the spectra in transmission that would be obtained during the primary transit, and then the spectra corresponding to the secondary transit, in emission.

\subsection{Transmission spectra}

The transmission synthetic spectra computed for the different atmospheres are represented in Fig. 7. As an example, Fig. 8 shows the relative contributions of the main opacity sources for the spectra corresponding to the $T_{1000}$ thermal profile.

For the $T_{500}$ profile, all the spectra are very similar because the atmospheric composition is also quite similar for the two $\mathrm{C} / \mathrm{O}$
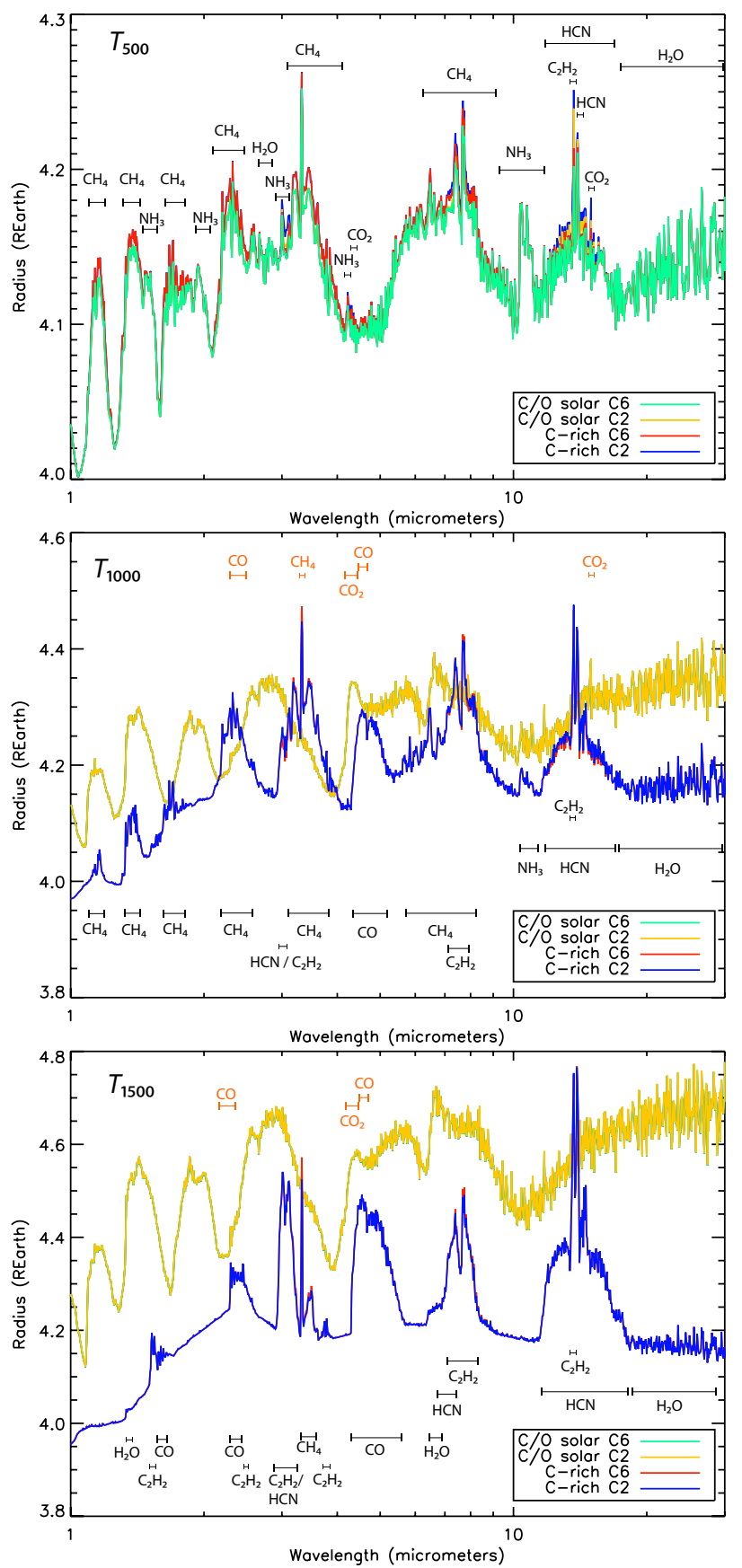

Fig. 7. Synthetic transmission spectra corresponding to the three thermal profiles $T_{500}$ (up), $T_{1000}$ (middle), and $T_{1500}$ (bottom), represented by the apparent radius. For each thermal profile, spectra have been calculated for the atmospheric compositions found using the $\mathrm{C}_{0}-\mathrm{C}_{2}$ and $\mathrm{C}_{0}-\mathrm{C}_{6}$ schemes for the cases $\mathrm{C} / \mathrm{O}=$ solar and $\mathrm{C} / \mathrm{O}=1.1$, as labelled in each figure. Main molecular features are indicated on each spectra. For the $T_{1000}$ and $T_{1500}$ cases, features for the $\mathrm{C} / \mathrm{O}$ solar spectra are plotted in orange and features for the $\mathrm{C}$-rich spectra in black.

ratio cases. The global form of the spectra is due to $\mathrm{H}_{2} \mathrm{O}$ and $\mathrm{CH}_{4}$. Most of the features are caused by the absorption of these species. In addition, we note the contribution of $\mathrm{NH}_{3}$ around 1.5 and $10.5 \mu \mathrm{m}$. There are two strong peaks beyond $10 \mu \mathrm{m}$. The first one, at $13.6 \mu \mathrm{m}$ is due to $\mathrm{C}_{2} \mathrm{H}_{2}$, and the second one, very close at $13.9 \mu \mathrm{m}$, is due to $\mathrm{HCN}$. A smaller peak is visible at $14.9 \mu \mathrm{m}$, which is caused by $\mathrm{CO}_{2}$. Despite their similarity, there are small departures between the spectra. The differences between the $\mathrm{C}$-rich (green, calculated with the $\mathrm{C}_{0}-\mathrm{C}_{6}$ scheme) and 

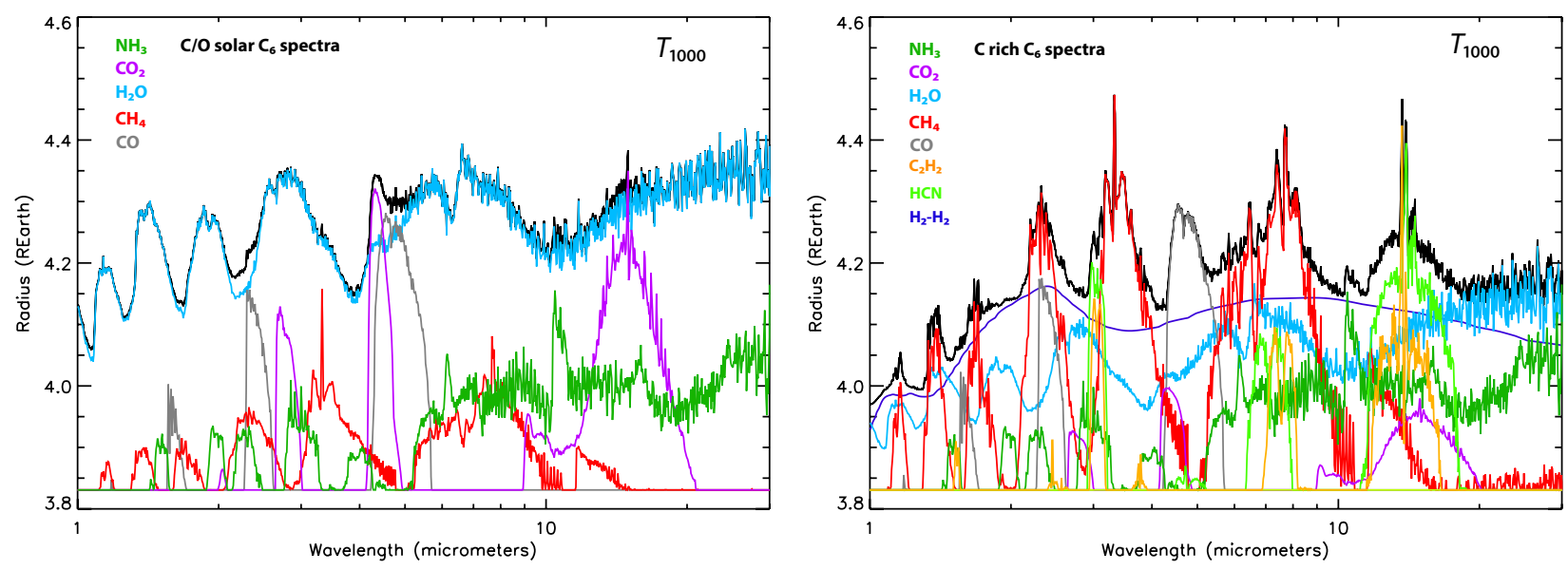

Fig. 8. Contributions of the main opacity sources to the synthetic transmission spectra corresponding to the thermal profile $T_{1000}$ for the cases $\mathrm{C} / \mathrm{O}=\operatorname{solar}($ left $)$ and $\mathrm{C} / \mathrm{O}=1.1$ (right). Spectra have been calculated for the atmospheric compositions found using the $\mathrm{C}_{0}-\mathrm{C}_{6} \mathrm{schemes}_{\text {. }}$

$\mathrm{C} / \mathrm{O}$ solar (red, calculated with the $\mathrm{C}_{0}-\mathrm{C}_{6}$ scheme) spectra are due to methane, which is more abundant in the $\zeta_{1.1}$ case. But there are also differences between spectra corresponding to the two chemical schemes at 3 and $4 \mu \mathrm{m}$, between 7 and $8 \mu \mathrm{m}$, and between 13 and $15 \mu \mathrm{m}$. The departure at $4 \mu \mathrm{m}$ is due to the difference of the mixing ratio of $\mathrm{CO}_{2}$ obtained when using the two schemes (blue vs. red for the $\zeta_{1.1}$ case and green vs. yellow for the $\zeta_{0.54}$ case), and all the others are due to $\mathrm{C}_{2} \mathrm{H}_{2}$, which is more abundant when using the $\mathrm{C}_{0}-\mathrm{C}_{2}$ scheme. This means that this species contributes more to the transmission spectra.

For the $T_{1000}$ profile, we observe strong differences between the spectra corresponding to the $\mathrm{C}$-rich and the $\mathrm{C} / \mathrm{O}$ solar cases. First, the global form of the $\mathrm{C} / \mathrm{O}$ solar spectra is due to $\mathrm{H}_{2} \mathrm{O}$, with contributions of $\mathrm{CO}_{2}$ around 4.2 and $15 \mu \mathrm{m}, \mathrm{CO}$ around 2.3 and $4.6 \mu \mathrm{m}$, and $\mathrm{CH}_{4}$ around $2.2 \mu \mathrm{m}$. There is no difference between the spectra corresponding to the results obtained with the $\mathrm{C}_{0}-\mathrm{C}_{2}$ and the $\mathrm{C}_{0}-\mathrm{C}_{6}$ schemes. The two $\mathrm{C}$-rich spectra are quite different from the $\mathrm{C} / \mathrm{O}$ solar spectra. Their form is mainly due to the $\mathrm{H}_{2}-\mathrm{H}_{2}$ collision-induced absorption, with contributions of several species: $\mathrm{CH}_{4}$ around 1.16, 1.38, 1.7, 2.3, $3.3 \mu \mathrm{m}$ and between 6 and $9 \mu \mathrm{m} ; \mathrm{HCN}$ around $3 \mu \mathrm{m}$ and at 13.9 and $14.2 \mu \mathrm{m}$; $\mathrm{CO}$ between 4.3 and $5.2 \mu \mathrm{m} ; \mathrm{C}_{2} \mathrm{H}_{2}$ around $3 \mu \mathrm{m}$ and at 7.4, 7.7, and $13.6 \mu \mathrm{m} ; \mathrm{NH}_{3}$ around $10.5 \mu \mathrm{m}$. $\mathrm{HCN}$ is the absorber that generates the features from 11 to $16 \mu \mathrm{m}$, and $\mathrm{H}_{2} \mathrm{O}$ is the main absorber from 16 to $30 \mu \mathrm{m}$. Unlike the $\zeta_{0.54}$ case, the two $\zeta_{1.1}$ spectra corresponding to the two chemical schemes present small departures. We found these deviations between 3 and $4 \mu \mathrm{m}$, between 7 and $8 \mu \mathrm{m}$, and between 13 and $15 \mu \mathrm{m}$. Like for the $T_{500}$ spectra, these departures are caused by the change of the abundance of $\mathrm{C}_{2} \mathrm{H}_{2}$ between the two chemical schemes, but also due to the lower mixing ratio of methane that we obtain when using the $\mathrm{C}_{0}-\mathrm{C}_{6}$ scheme.

For the $T_{1500}$ profile, we also observe departures between the spectra corresponding to the two $\mathrm{C} / \mathrm{O}$ ratios. For the $\mathrm{C} / \mathrm{O}$ solar spectra, the contributing species are the same as for the $T_{1000}$ profile: $\mathrm{H}_{2} \mathrm{O}$ everywhere except around 2.3 and $4.6 \mu \mathrm{m}$ (CO) and around $4.2 \mu \mathrm{m}\left(\mathrm{CO}_{2}\right)$. The peak of $\mathrm{CO}_{2}$ at $15 \mu \mathrm{m}$ is not visible because of the very much lower abundance of this species in the atmosphere. This area of the spectra is entirely dominated by water. We note that once again, there is no difference between the spectra corresponding to the two chemical schemes, which is expected because there is also no difference in the computed chemical abundances. The spectra of the C-rich atmosphere are different from the $\mathrm{C} / \mathrm{O}$ solar spectra. Like for the $T_{1000}$ profile, their form is due to the $\mathrm{H}_{2}-\mathrm{H}_{2}$ collision. There are contributions of $\mathrm{H}_{2} \mathrm{O}$ around $1.35 \mu \mathrm{m}$ and from $18 \mu \mathrm{m}$ until the end of the computed spectra $(30 \mu \mathrm{m})$. There are many contribution of $\mathrm{C}_{2} \mathrm{H}_{2}$ : around $1.5,2.45,3,3.7,7.4,7.7$, and the very high peak at $13.6 \mu \mathrm{m}$. We see $\mathrm{CO}$ features at 1.6, 2.3, and $4.6 \mu \mathrm{m}$. The contribution of $\mathrm{CH}_{4}$ is very small compared to the two previous cases $\left(T_{500}\right.$ and $\left.T_{1000}\right)$. There is a strong peak at $3.32 \mu \mathrm{m}$ and a smaller peak around $3.49 \mu \mathrm{m}$. Methane is also responsible for the absorption peak at $7.39 \mu \mathrm{m}$, which is almost mingled with the two strong acetylene peaks. Finally, the last contributing molecule is $\mathrm{HCN}$ with its peaks around 3, 7, 13.9, and $14.2 \mu \mathrm{m}$. HCN is also responsible for the features from 11 to $18 \mu \mathrm{m}$. These results agree with what has been found for WASP$12 \mathrm{~b}$ by Kopparapu et al. (2012).

\subsection{Emission spectra}

Figure 9 presents the synthetic emission spectra obtained for our 12 atmospheres. As for the transmission spectra, for the cool atmosphere, there is almost no difference between the emission spectra of the two different $\mathrm{C} / \mathrm{O}$ ratios, whereas for the two warmer profiles the emission spectra are clearly different depending on the $\mathrm{C} / \mathrm{O}$ ratio of the atmosphere. For the $\mathrm{C} / \mathrm{O}$ solar cases, the spectra are dominated by the absorption of $\mathrm{H}_{2} \mathrm{O}$ for the two warmer cases and by water and methane for the $T_{500}$ profile. For the C-rich cases, as we explained for transmission spectra in Sect. 4.1, the spectra are dominated by the $\mathrm{H}_{2}-\mathrm{H}_{2}$ collision, with contributions of other species, such as $\mathrm{C}_{2} \mathrm{H}_{2}, \mathrm{HCN}$, and $\mathrm{CH}_{4}$.

The analysis of these emission and transmission spectra shows us that $\mathrm{C}_{2} \mathrm{H}_{2}$ and $\mathrm{HCN}$ can be considered as good tracers of the $\mathrm{C} / \mathrm{O}$ ratio if the atmosphere presents a sufficiently high temperature (above $800 \mathrm{~K}$ ), thanks to their peaks at 7.4, 7.7, 13.6, 13.9, and $14.2 \mu \mathrm{m}$, respectively, visible when $\mathrm{C} / \mathrm{O}=1.1$. For lower temperatures, acetylene and hydrogen cyanide present similar mixing ratios in the two $\mathrm{C} / \mathrm{O}$ cases that we tested and thus cannot give information on the $\mathrm{C} / \mathrm{O}$ ratio of the atmosphere. As emphasised by Madhusudhan (2012), these two species absolutely need to be considered in spectra models to interpret and understand observations of exoplanets atmospheres.

\section{Conclusions}

We have developed a new chemical scheme for studying C-rich atmospheres. This $\mathrm{C}_{0}-\mathrm{C}_{6}$ scheme describes the kinetics of 240 species that contain up to six carbon atoms and are involved 
O. Venot et al.: New chemical scheme for studying carbon-rich exoplanet atmospheres
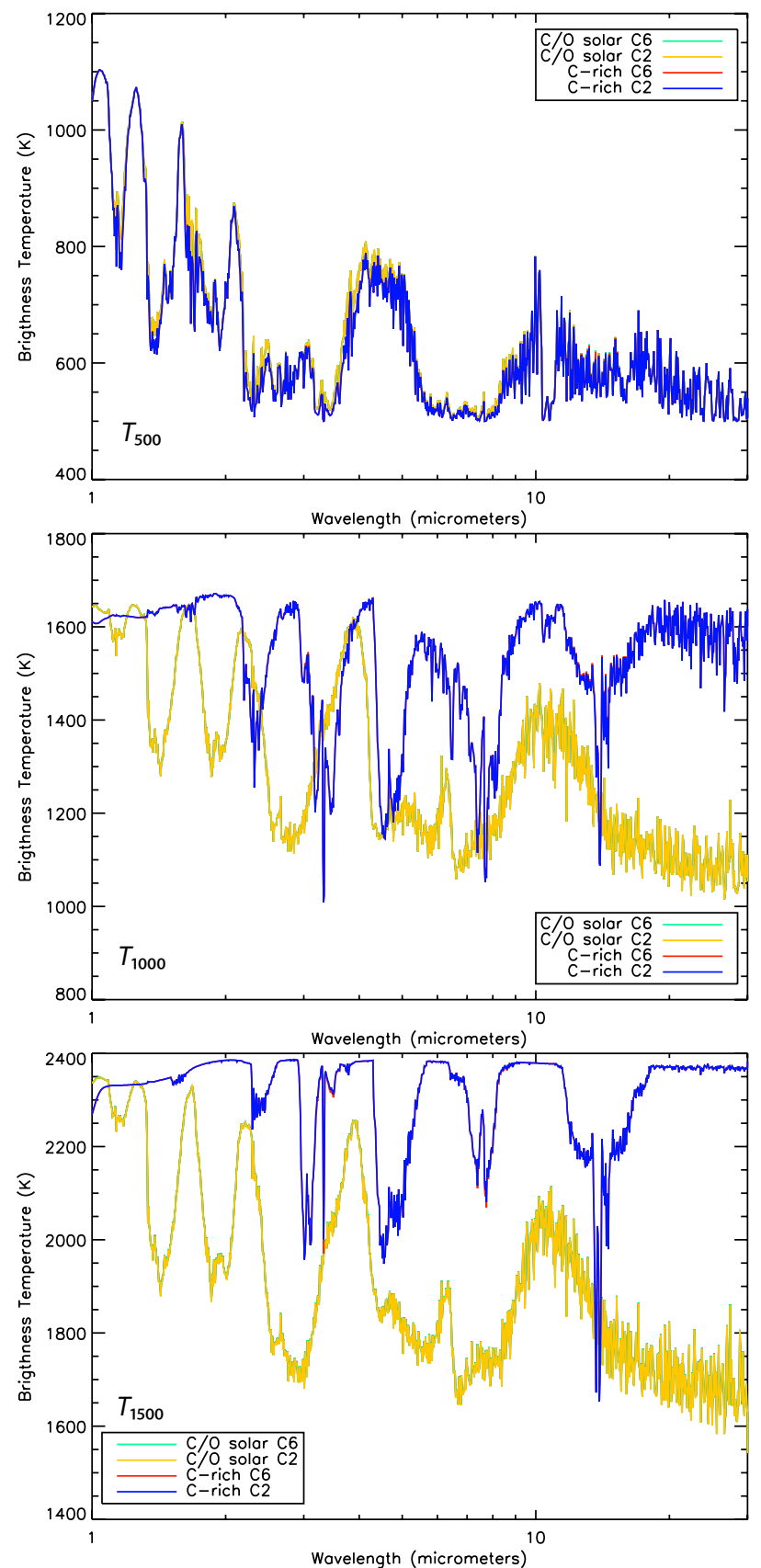

Fig. 9. Synthetic emission spectra corresponding to the three thermal profiles $T_{500}(u p), T_{1000}$ (middle), and $T_{1500}$ (bottom), represented by the brightness temperature $(\mathrm{K})$. For each thermal profile, spectra have been calculated with the atmospheric compositions found with the $\mathrm{C}_{0}-\mathrm{C}_{2}$ and $\mathrm{C}_{0}-\mathrm{C}_{6}$ schemes for the cases $\mathrm{C} / \mathrm{O}=$ solar and $\mathrm{C} / \mathrm{O}=1.1$, as labelled in each figure.

in 4002 reactions. It is available in the online database $\mathrm{KIDA}^{5}$ (Wakelam et al. 2012). We used this chemical scheme to study atmospheres with different thermal profiles and $\mathrm{C} / \mathrm{O}$ ratios and compared the results obtained with those obtained with a smaller chemical scheme $\left(\mathrm{C}_{0}-\mathrm{C}_{2}\right.$, described in Venot et al. 2012). When photodissociation is neglected, the two chemical schemes yield identical results. This strengthens the robustness of the small $\mathrm{C}_{0^{-}}$ $\mathrm{C}_{2}$ scheme. It perfectly described the kinetics of $\mathrm{C}_{2}$ species, and even a scheme that contains twice more reactions gives the same results.

\footnotetext{
5 http://kida.obs.u-bordeaux1.fr/models/
}

The introduction of the photodissociations induces, in some cases, differences between the two chemical schemes. With the warm and hot profiles $(\sim 1000 \mathrm{~K}$ and $\sim 1500 \mathrm{~K})$, there are differences when the $\mathrm{C} / \mathrm{O}$ ratio of the atmosphere is high (1.1), but not when it is solar. This is mainly due to $\mathrm{C}_{2} \mathrm{H}_{2}$, which is much more abundant in a $\mathrm{C}$-rich atmosphere and participates in the $\mathrm{C}_{0}-\mathrm{C}_{6}$ scheme in formation pathways involving heavy hydrocarbons. For the cool profile $(\sim 500 \mathrm{~K})$, there are differences between the two schemes regardless of the $\mathrm{C} / \mathrm{O}$ ratio of the atmosphere. Here again, the high amount of $\mathrm{C}_{2} \mathrm{H}_{2}$ in the upper atmosphere is responsible for this. Nevertheless, the differences obtained using the two chemical schemes do not create differences in the synthetic spectra. The analysis of the synthetic spectra corresponding to the 12 different cases has highlighted the fact the absorption features around 7 and $14 \mu \mathrm{m}$ due to $\mathrm{C}_{2} \mathrm{H}_{2}$ and $\mathrm{HCN}$ can be used as tracers of the $\mathrm{C} / \mathrm{O}$ ratio for atmospheres with temperatures higher than $800 \mathrm{~K}$.

In conclusion, our advice for using of one or the other chemical scheme is as follows:

- In warm atmospheres $(T \geq 1000 \mathrm{~K})$ with solar $\mathrm{C} / \mathrm{O}$ ratios, the $\mathrm{C}_{0}-\mathrm{C}_{2}$ scheme is sufficient.

- In cooler atmospheres (regardless of the $\mathrm{C} / \mathrm{O}$ ratio) or warm atmospheres with a $\mathrm{C} / \mathrm{O}$ ratio higher than 1 , the choice of the chemical scheme depends on the goal of the study. If the focus is on computing synthetic spectra, then the use of the $\mathrm{C}_{0}-\mathrm{C}_{2}$ scheme is a reasonable choice because the computation time will be shorter. But if the chemical composition is to be studied in detail and the chemical pathways occurring in the atmosphere are to be understood, then using the more complete $\mathrm{C}_{0}-\mathrm{C}_{6}$ scheme is advised.

We recall that the mixing ratios calculated here could change by several orders of magnitude if absorption cross-sections at high temperatures are used for all the absorbing species present in the chemical network. We only used hot data for $\mathrm{CO}_{2}$ (Venot et al. 2013) and $\mathrm{NH}_{3}$ (Venot et al. in prep.), but measurements of other species are much needed. In particular, this study shows that $\mathrm{C}_{2} \mathrm{H}_{2}$ should be the next target of these experiments.

Acknowledgements. O.V. acknowledges support from the KU Leuven IDO project IDO/10/2013 and from the FWO Postdoctoral Fellowship programme. The authors thank I. Baraffe, M. Dobrijevic, and F. Selsis for useful discussions. We also thank the anonymous referee for comments that much improved the manuscript.

\section{References}

Agúndez, M., Parmentier, V., Venot, O., Hersant, F., \& Selsis, F. 2014a, A\&A, 564, A73

Agúndez, M., Venot, O., Selsis, F., \& Iro, N. 2014b, ApJ, 781, 68

Belmekki, N., Glaude, P., Da Costa, I., Fournet, R., \& Battin-Leclerc, F. 2002, Int. J. Chem. kinet., 34, 172

Benson, S. W. 1976, Thermochemical Kinetics: methods for the estimation of thermochemical data and rate parameters, 2nd edn. (New York: John Wiley \& Sons)

Bounaceur, R., Da Costa, I., Fournet, R., Billaud, F., \& Battin-Leclerc, F. 2005, Int. J. Chem. Kinet., 37, 25

Burrows, A., Hubeny, I., Budaj, J., Knutson, H. A., \& Charbonneau, D. 2007, ApJ, 668, L171

Charbonneau, D., Brown, T. M., Noyes, R. W., \& Gilliland, R. L. 2002, ApJ, 568,377

Crossfield, I. J. M., Barman, T., Hansen, B. M. S., Tanaka, I., \& Kodama, T. 2012, ApJ, 760, 140

Da Costa, I., Fournet, R., Billaud, F., \& Battin-Leclerc, F. 2003, Int. J. Chem. Kinet., 35, 503

Désert, J.-M., Vidal-Madjar, A., Lecavelier Des Etangs, A., et al. 2008, A\&A, 492,585 
Diamond-Lowe, H., Stevenson, K. B., Bean, J. L., Line, M. R., \& Fortney, J. J. 2014, ApJ, 796, 66

Dirrenberger, P., Le Gall, H., Bounaceur, R., et al. 2011, Energy and Fuels, 25, 3875

Dobrijevic, M., Hébrard, E., Loison, J. C., \& Hickson, K. M. 2014, Icarus, 228, 324

Fournet, R., Baugé, J., \& Battin-Leclerc, F. 1999, Int. J. Chem. Kinet., 31, 361

Gueniche, H.-A., Biet, J., Glaude, P.-A., Fournet, R., \& Battin-Leclerc, F. 2009, Fuel, 88, 1388

Hébrard, E., Dobrijevic, M., Loison, J. C., et al. 2013, A\&A, 552, A132

Hidaka, Y., Higashihara, T., Ninomiya, N., et al. 1996, Int. J. Chem. Kinet., 28, 137

Kee, R., Rupley, F., Meeks, E., \& Miller, J. 1996, CHEMKIN-III: A FORTRAN chemical kinetics package for the analysis of gas-phase chemical and plasma kinetics (Sandia National Laboratories Livermore, CA)

Keller-Rudek, H., Moortgat, G. K., Sander, R., \& Sörensen, R. 2013, J. Earth Syst. Sci. Data, 5, 365

Knutson, H. A., Charbonneau, D., Allen, L. E., Burrows, A., \& Megeath, S. T. 2008, ApJ, 673, 526

Kopparapu, R. K., Kasting, J. F., \& Zahnle, K. J. 2012, ApJ, 745, 77

Lehmann, R. 2004, J. Atm. Chem., 47, 45

Lewis, N. K., Showman, A. P., Fortney, J. J., et al. 2010, ApJ, 720, 344

Liang, M., Parkinson, C., Lee, A., Yung, Y., \& Seager, S. 2003, ApJ, 596, L247

Liang, M., Seager, S., Parkinson, C., Lee, A., \& Yung, Y. 2004, ApJ, 605, L61

Lindstedt, R., \& Maurice, L. 1996, Combust. Sci. Technol., 120, 119

Line, M., Liang, M., \& Yung, Y. 2010, ApJ, 717, 496

Line, M., Vasisht, G., Chen, P., Angerhausen, D., \& Yung, Y. 2011, ApJ, 738, 32

Madhusudhan, N. 2012, ApJ, 758, 36

Madhusudhan, N., Harrington, J., Stevenson, K. B., et al. 2011a, Nature, 469, 64

Madhusudhan, N., Mousis, O., Johnson, T. V., \& Lunine, J. I. 2011b, ApJ, 743, 191

Madhusudhan, N., Crouzet, N., McCullough, P. R., Deming, D., \& Hedges, C. 2014a, ApJ, 791, L9

Madhusudhan, N., Knutson, H., Fortney, J., \& Barman, T. 2014b, Protostars and Planets VI, eds. H. Beuther, R. S. Klessen, C. P. Dullemond, \& Th. Henning. (Tucson: University of Arizona Press), 739

Mandell, A. M., Haynes, K., Sinukoff, E., et al. 2013, ApJ, 779, 128
McCullough, P., \& MacKenty, J. 2012, Considerations for using Spatial Scans with WFC3, Tech. Rep.

Miller, J., \& Melius, C. 1992, Combustion and Flame, 91, 21

Miller-Ricci Kempton, E., Zahnle, K., \& Fortney, J. J. 2012, ApJ, 745, 3

Moses, J. I., Visscher, C., Fortney, J. J., et al. 2011, ApJ, 737, 15

Moses, J., Madhusudhan, N., Visscher, C., \& Freedman, R. 2013a, ApJ, 763, 25

Moses, J., Line, M., Visscher, C., et al. 2013b, ApJ, 777, 34

Muller, C., Michel, V., Scacchi, G., \& Côme, G. 1995, J. Chim. Phys., 92, 1154

Parmentier, V., \& Guillot, T. 2014, A\&A, 562, A133

Parmentier, V., Showman, A. P., \& Lian, Y. 2013, A\&A, 558, A91

Parmentier, V., Showman, A. P., \& de Wit, J. 2015, Exp. Astron., in press, ArXiv e-prints [arXiv: 1401.3673]

Parmentier, V., Guillot, T., Fortney, J. J., \& Marley, M. S. 2015, A\&A, 574, A35

Redfield, S., Endl, M., Cochran, W. D., \& Koesterke, L. 2008, ApJ, 673, L87

Rothman, L., Gordon, I., Babikov, Y., et al. 2013, J. Quant. Spect. Rad. Transf., 130,4

Sing, D. K., Désert, J.-M., Fortney, J. J., et al. 2011, A\&A, 527, A73

Stevenson, K. B., Bean, J. L., Seifahrt, A., et al. 2014, AJ, 147, 161

Stock, J. W., Boxe, C. S., Lehmann, R., et al. 2012, Icarus, 219, 13

Swain, M., Tinetti, G., Vasisht, G., et al. 2009a, ApJ, 704, 1616

Swain, M., Vasisht, G., Tinetti, G., et al. 2009b, ApJ, 690, L114

Swain, M., Deroo, P., Tinetti, G., et al. 2013, Icarus, 225, 432

Thuillier, G., Floyd, L., Woods, T., et al. 2004, Adv. Space Res., 34, 256

Troe, J. 1974, Berichte der Bunsengesellschaft für Physikalische Chemie, 78, 478

Tsang, W. 1991, J. Phys. Chem. Ref. Data, 20, 221

Valencia, D., Guillot, T., Parmentier, V., \& Freedman, R. S. 2013, ApJ, 775, 10

Venot, O., Hébrard, E., Agúndez, M., et al. 2012, A\&A, 546, A43

Venot, O., Fray, N., Bénilan, Y., et al. 2013, A\&A, 551, A131

Venot, O., Agúndez, M., Selsis, F., Tessenyi, M., \& Iro, N. 2014, A\&A, 562, A51

Visscher, C., \& Moses, J. I. 2011, ApJ, 738, 72

Wakelam, V., Herbst, E., Loison, J.-C., et al. 2012, ApJS, 199, 21

Wang, H., \& Frenklach, M. 1997, Combustion and Flame, 110, 173

Westmoreland, P., Dean, A., Howard, J., \& Longwell, J. 1989, Combustion and Flame, 77, 145

Zahnle, K., Marley, M., Freedman, R., Lodders, K., \& Fortney, J. 2009, ApJ, 701, L20 